\title{
Graphene-supported metal single-atom catalysts: a concise review
}

\author{
Shuai Ren ${ }^{1}, \mathrm{Qi} \mathrm{Yu}^{1^{*}}$, Xiaohu Yu${ }^{2}$, Ping Rong ${ }^{1}$, Liyun Jiang ${ }^{3}$ and Jianchao Jiang ${ }^{1}$
}

\begin{abstract}
Single-atom catalysts (SACs) have become an emerging frontier trend in the field of heterogeneous catalysis due to their high activity, selectivity and stability. SACs could greatly increase the availabilities of the active metal atoms in many catalytic reactions by reducing the size to single atom scale. Graphene-supported metal SACs have also drawn considerable attention due to the unique lattice structure and physicochemical properties of graphene, resulting in superior activity and selectivity for several chemical reactions. In this paper, we review recent progress in the fabrications, advanced characterization tools and advantages of graphene-supported metal SACs, focusing on their applications in catalytic reactions such as CO oxidation, the oxidation of benzene to phenol, hydrogen evolution reaction, methanol oxidation reaction, oxygen reduction reaction, hydrogenation and photoelectrocatalysis. We also propose the development of SACs towards industrialization in the future.
\end{abstract}

Keywords: single-atom catalysts, graphene substrate, advanced characterization methods, catalytic reaction

\section{INTRODUCTION}

It is necessary for a heterogeneous catalysis reaction to undergo three processes: first, the reactants must be chemically adsorbed on the catalyst surface; second, the reactants are transformed; and finally the products need to desorb from the catalyst surface. Therefore, the solidsupporting catalytic substrate plays a very important role in the processes. Although the metal loadings on traditional heterogeneous catalysts are high, the majority of active metal species are buried below the surface of the nanoparticles. The low catalytic efficiency can hardly satisfy the demands of industrialization $[1,2]$. Therefore, it is crucial to reduce the size of precious metal catalysts to promote the catalytic efficiency. When the size of the precious metal catalysts is reduced to the sub-nanometer level, the precious metals on the catalyst surface are isolated from each other, which can significantly improve the catalytic efficiency $[3,4]$. Single-atom catalysts (SACs) have been playing important roles in the field of catalysis since they were proposed [5-9]. Qiao et al. [5] prepared the $\mathrm{Pt} / \mathrm{FeO}_{x}$ catalysts by anchoring single $\mathrm{Pt}$ atoms on the surface of $\mathrm{FeO}_{x}$ and proposed the concept of SACs for the first time. The catalysts with high activity and stability significantly increased the utilization of precious metal atoms. Sahoo et al. [10] proved that non-precious metal SACs could also achieve enhanced $\mathrm{C}-\mathrm{H}$ bond methane activation by using theoretical calculations.

Graphene, as the thinnest two-dimensional (2D) carbon material with one atom thickness $(0.334 \mathrm{~nm})$ [11-14], has been widely used in many fields. Its unique and stable lattice structure results in excellent thermal conductivity $[15,16]$, electrical conductivity [17-20], large specific surface area [21-23] and facile chemical modification [24-26]. Graphene has also been reported to be an excellent support for SACs due to its remarkable properties [27-34]. Liang et al. [35] compounded bi-functional $\mathrm{Co}_{3} \mathrm{O}_{4} /$ reduced graphene oxide (RGO) catalysts with excellent durability and activity. Li et al. [36] fabricated $\mathrm{MoS}_{2}$ nanoparticles supported on RGO by a selective solvothermal method, which presented excellent electrocatalytic performance in the hydrogen evolution reaction (HER).

However, the deposition of single metal atoms on the graphene surface remains challenging. Firstly, the interaction between metal atoms and the graphene surface is

\footnotetext{
${ }^{1}$ School of Materials Science and Engineering, Institute of Graphene at Shaanxi Key Laboratory of Catalysis, Shaanxi University of Technology, Hanzhong 723001, China

${ }^{2}$ School of Chemistry and Environmental Science, Shaanxi Key Laboratory of Catalysis, Shaanxi University of Technology, Hanzhong 723001, China

${ }^{3}$ School of Physics and Telecommunication Engineering, Shaanxi University of Technology, Hanzhong 723001, China

* Corresponding authors (email: kukukoko2004@163.com)
} 
weak, which leads to instability during catalytic reactions [9]. Secondly, it is difficult to obtain graphene-supported SACs. Finally, reducing the size of metal catalysts definitely results in significant aggregation, causing deactivation of the catalysts during catalytic reactions [37]. In this review, we introduced diverse preparation methods and advantages of graphene-supported metal SACs aimed at solving the above-mentioned challenges. We also summarized their applications in CO oxidation [5,38-40], oxidation of benzene to phenol [41], HER [42,43], methanol oxidation reaction (MOR) [44-46], oxygen reduction reaction (ORR) [47-50], hydrogenation [32,51] and photoelectrocatalysis [52-55]. At last, we focused on the prospect and future developments of graphene-supported metal SACs.

\section{SELECTION OF SUBSTRATES}

\section{Metal substrates and metal oxide substrates}

With the decreasing size of active metals, the metal catalysts can achieve enhanced catalytic activity while bringing large surface free energy [8], which is an important reason for the instability of conventional metalsupported SACs (Fig. 1). Therefore, the choice of substrate is the key to the synthesis of stable SACs. The substrates of supported catalysts can be divided into traditional metal substrate, metal oxide substrate and new 2D material substrate. Many outstanding active metals of SACs, such as Pt [56,57], Au [58], Pd [59], Fe [60-62], Co [63-65], Ni [66] and $\mathrm{Cr}$ [67], have exhibited extraordinary activity in many catalytic reactions. There are also some common metal-oxide supporting substrates of SACs, such as $\mathrm{FeO}_{x}$ [5], $\mathrm{TiO}_{2}$ [68], $\mathrm{ZrO}_{2}$ [69] and $\mathrm{ZnO}$ [70]. Metal SACs can be synthesized by general methods, such as mass-selected soft-landing technique [71], coprecipitation [72], successive reduction [73] and solid phase melting method [74], etc.

Zhang et al. [73] prepared single Au atoms supported on $\mathrm{Pd}(\mathrm{Au} / \mathrm{Pd}$ catalysts) by the successive reduction method. Their results showed that the catalytic efficiency of $\mathrm{Au} / \mathrm{Pd}$ catalysts was 17 times higher than the Au nanoparticle catalysts, which indicated excellent catalytic performance of $\mathrm{Au} / \mathrm{Pd}$ catalysts. The metal/metal catalysts (single metal atoms anchored to the surface of metal supporting substrate) and metal/metal-oxide catalysts (single metal atoms anchored to the surface of metaloxide supporting substrate) exhibited high activity, good chemical selectivity and durability. However, there are still obvious defects in the metal and metal-oxides as catalytic substrates. As substrates, the catalytic efficiency of or-

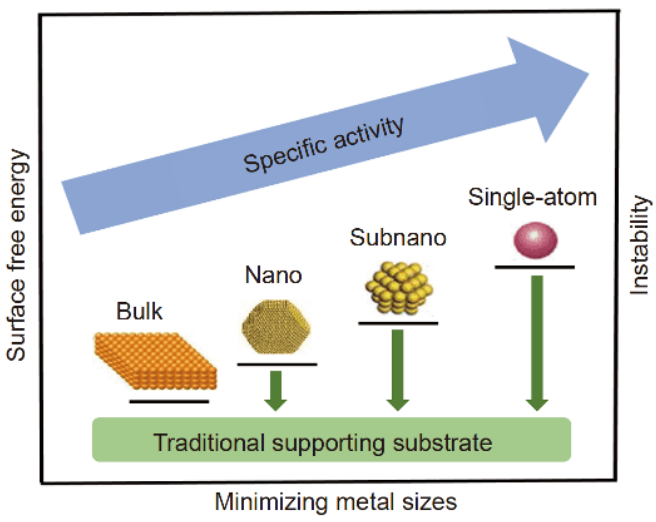

Figure 1 Schematic diagram illustrating the relationships of surface free energy, instability and specific activity per metal atom on traditional supporting substrate with metal size.

dinary metals is lower than precious metals. Otherwise, there are also some shortcomings of catalysts such as high cost, low light-off temperature and easy-sintering at high temperature, which prove problematic for the application on industrial scale. Thus, we should explore high-efficiency, low-temperature and non-metal SAC substrates.

\section{D material substrates}

Graphene has become the emerging non-metal substrate of SACs due to its unique 2D structure, good mechanical properties and conductivity [54,75-82]. The honeycomblike sheet of graphene will provide more active sites, and the porous structure will effectively reduce the agglomeration of metal atoms [30,83]. Sahoo et al. [84] calculated the possibility of depositing single transition metal (TM) atoms, such as $\mathrm{Cr}, \mathrm{Mn}, \mathrm{Fe}, \mathrm{Co}$, and $\mathrm{Cu}$ atoms, on the surface of graphene by density functional theory (DFT). The results showed that the single-atom TM/graphene catalysts exhibited a high activity in the methane activation reaction. Graphene as a support has been proven to be stable during different catalytic reactions, such as $\mathrm{CO}$ oxidation and hydrogenation, due to superior chemical compatibility and surface-modification chemistry $[32,40]$. At present, the main methods for preparation of graphene-supported metal SACs include atomic layer deposition (ALD) [30], focused electron beam irradiation [85], ethylene glycol (EG) reduction [50], high-energy ball milling [41] and arc discharge method [86], etc.

\section{Graphene substrate}

Wang et al. [87] obtained single Si atoms supported on graphene (Si/graphene catalysts) by a chemical vapor deposition (CVD) method. Single Si atoms, as a catalytic wedge in the form of energetic electrons, were observed 
by high-resolution transmission electron microscopy (HRTEM) (Fig. 2a). The $\mathrm{C}$ atom of graphene was gradually replaced by $\mathrm{Si}$ atom to form a stable structure. Fig. $2 b$ demonstrates the catalytic mechanism of the single Si ad-atom on the surface and edges of graphene. The experimental results showed that Si/graphene catalysts with dynamic, stability and high selectivity provided the possibility for developing stable molecular devices at the atomic scale.

Liu et al. [39] reported the Pt/graphene catalysts by simulating single $\mathrm{Pt}$ atoms embedded into graphene lattice via first principles and DFT calculations. The calculation showed that the binding energy was up to $-0.71 \mathrm{eV}$, which enhanced the stability of the catalysts. Diffusion and agglomeration of embedded Pt atoms were thus effectively avoided. When the regenerative energy barrier of Pt atoms reached $0.46 \mathrm{eV}$, the energy barriers for the formation and dissociation of the peroxide-like intermediate were only 0.33 and $0.15 \mathrm{eV}$, respectively, which also showed the superior activity of Pt-embedded graphene catalysts in low temperature $\mathrm{CO}$ oxidation reaction.

Zhao et al. [34] observed single Fe atoms at the graphene edges by in situ atomically resolved TEM and discovered anomalous diffusion. The carbon atoms were directly substituted by or merged with single $\mathrm{Fe}$ atoms. High catalytic performance of single Fe atoms was consistent with the result of theoretical calculations (molecular dynamic simulations and DFT), which could contribute to the basis for the $\mathrm{sp}^{2}$ carbon growth of graphene-supported metal SACs.

\section{Nitrogen-doped graphene substrate}

Fei et al. [43] synthesized single Co atoms supported on nitrogen-doped graphene (Co/N-graphene catalysts) with graphene oxide (prepared by modified Hummers method) in the $\mathrm{Ar} / \mathrm{NH}_{3}$ atmosphere for $1 \mathrm{~h}$ (Fig. 3a). The $\mathrm{Co} /$ $\mathrm{N}$-graphene catalysts exhibited high activity, stability and low overpotentials $(30 \mathrm{mV})$, which was due to the coordinating role of nitrogen atoms in the substrate center (Fig. 3b-d).

Zhang et al. [40] synthesized single Pt atoms supported on nitrogen-doped graphene (Pt/N-graphene catalysts) with high stability and activity in CO oxidation. The stability of single Pt atoms could be improved by suitable doping. They had much higher stability, activity and lower energy barrier $(0.16 \mathrm{eV})$ through tri-molecular a

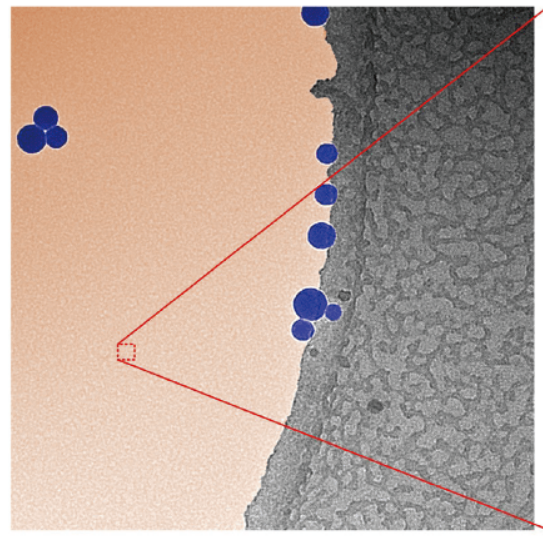

b

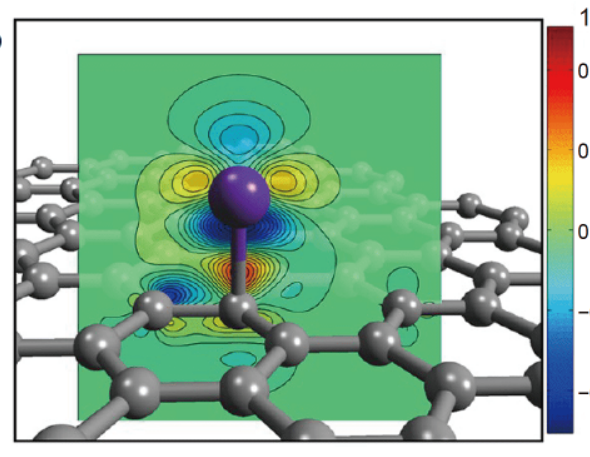

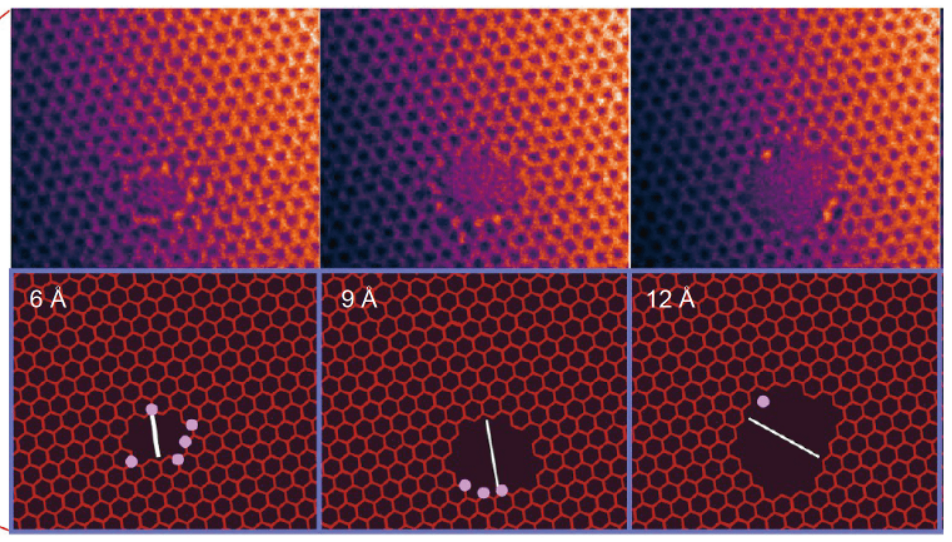

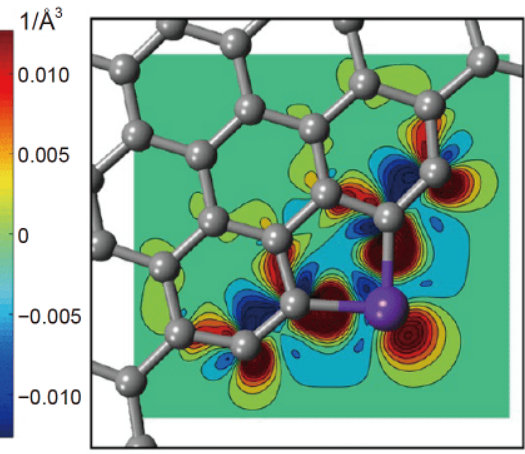

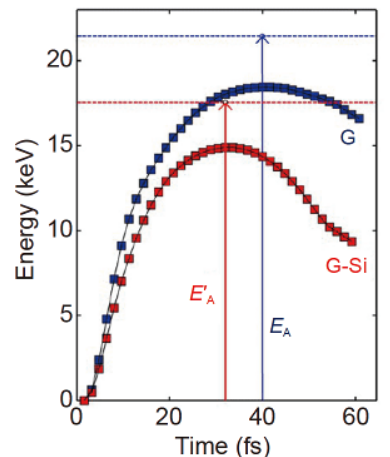

Figure 2 (a) HRTEM images of silicon/graphene sample, (b) catalytic principles of the single Si ad-atom. Reprinted with permission from Ref. [87], Copyright 2016, American Chemical Society. 


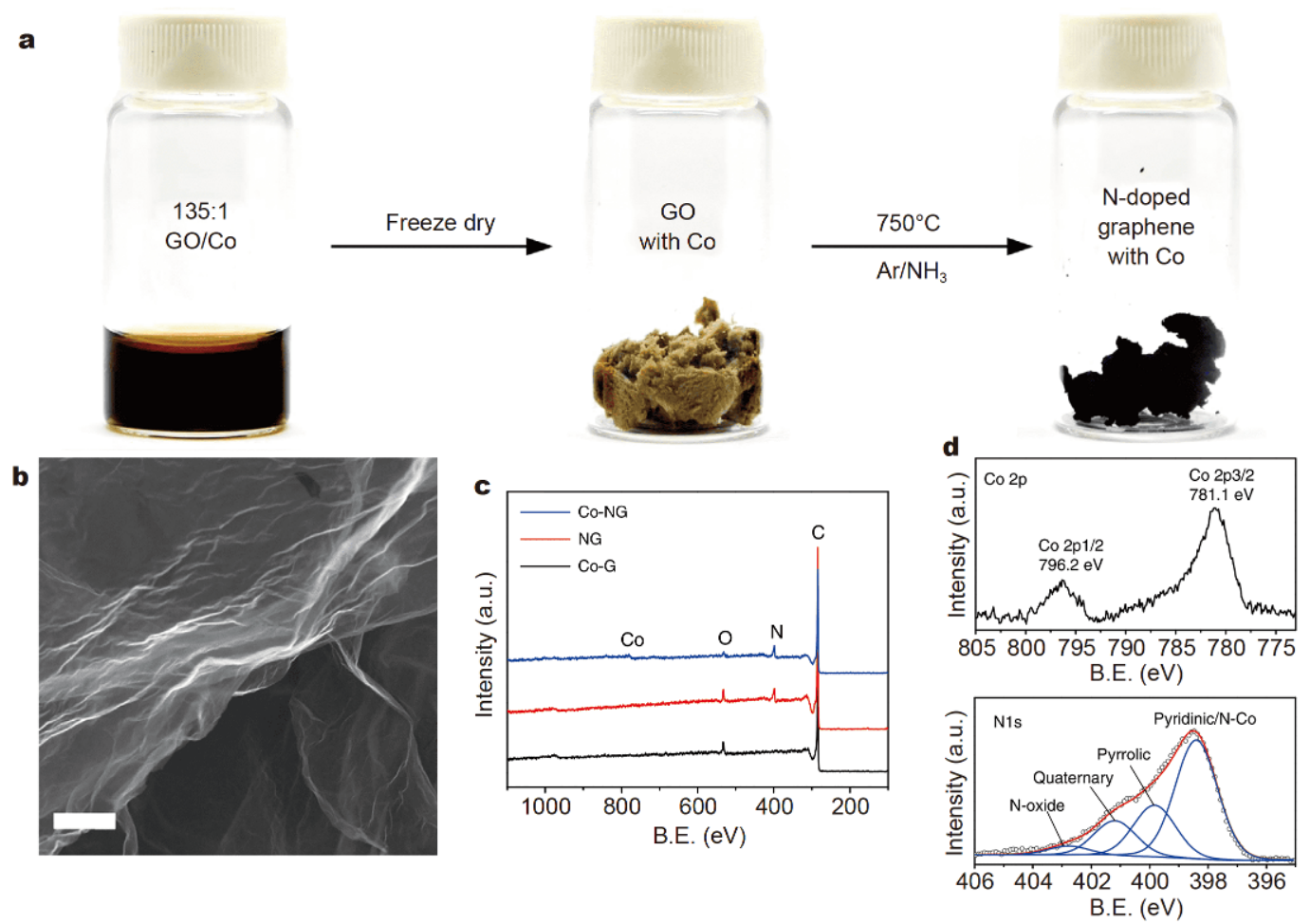

Figure 3 Preparation, morphology and compositional characterizations of the Co-NG. (a) Preparation process of the Co-NG catalyst, (b) SEM image, (c) XPS spectra (NG represents N-graphene), (d) HR XPS Co 2p and N 1s spectra. Reprinted with permission from Ref. [43], Copyright 2015, Nature Publishing Group.

Eley-Rideal mechanism, which was obviously better than Langmuir-Hinshelwood or Eley-Rideal mechanisms for $\mathrm{CO}$ oxidation.

Single Ni atoms supported on nitrogen-doped graphene (Ni/N-graphene catalysts) were prepared with $\mathrm{N}$-graphene as catalytic substrate by Yang et al. [88], with the process of zirconia ball grinding, pyrolysis, freeze-drying and reheating under an argon atmosphere. The Ni/Ngraphene catalysts could retain $98 \%$ of original catalytic performance after $\mathrm{CO}_{2}$ reduction for $100 \mathrm{~h}$.

Graphene is the nucleation center of single metal atoms to exert the maximum catalytic activity in chemical reactions. The large specific surface area can provide plenty of effective active sites for single metal atoms. Nevertheless, efficient and cost-effective preparation methods of graphene-supported metal SACs are critical.

\section{PREPARATION METHODS OF GRAPHENE-SUPPORTED METAL SACs}

ALD

For ALD, single atom layer is coated to the target surface through a reactor. The film deposition quality of tradi- tional CVD is related to several factors, such as deposition time, temperature and gas flow. Compared with conventional CVD method, ALD is a novel technique depositing a thin film by different precursors. It has many advantages in terms of film formation uniformity, quality and number of layers, which can be mainly used in the fields of semiconductor [89-91] and nanotechnology [9294]. In recent years, ALD has been frequently applied in the field of catalysis. This technique can precisely control the morphology, size, density and loading of single metal atoms, sub-nanoclusters and nanoparticles.

Sun et al. [30] prepared single Pt atoms supported on graphene nanosheets (Pt/GNS catalysts) by the ALD technique. Fig. 4a shows the schematic of Pt ALD on graphene surface. The isolated and well-grown single $\mathrm{Pt}$ atoms were uniformly deposited on the graphene surface as confirmed by high-angle annular dark field scanning transmission electron microscopy (HAADF-STEM). By changing the number and conditions of ALD cycles, the morphology, size, density and loading of single Pt atoms could be efficiently controlled. When the numbers of ALD cycles reached 50, the methanol oxidation peak current density for 50ALD Pt/GNS catalysts was 

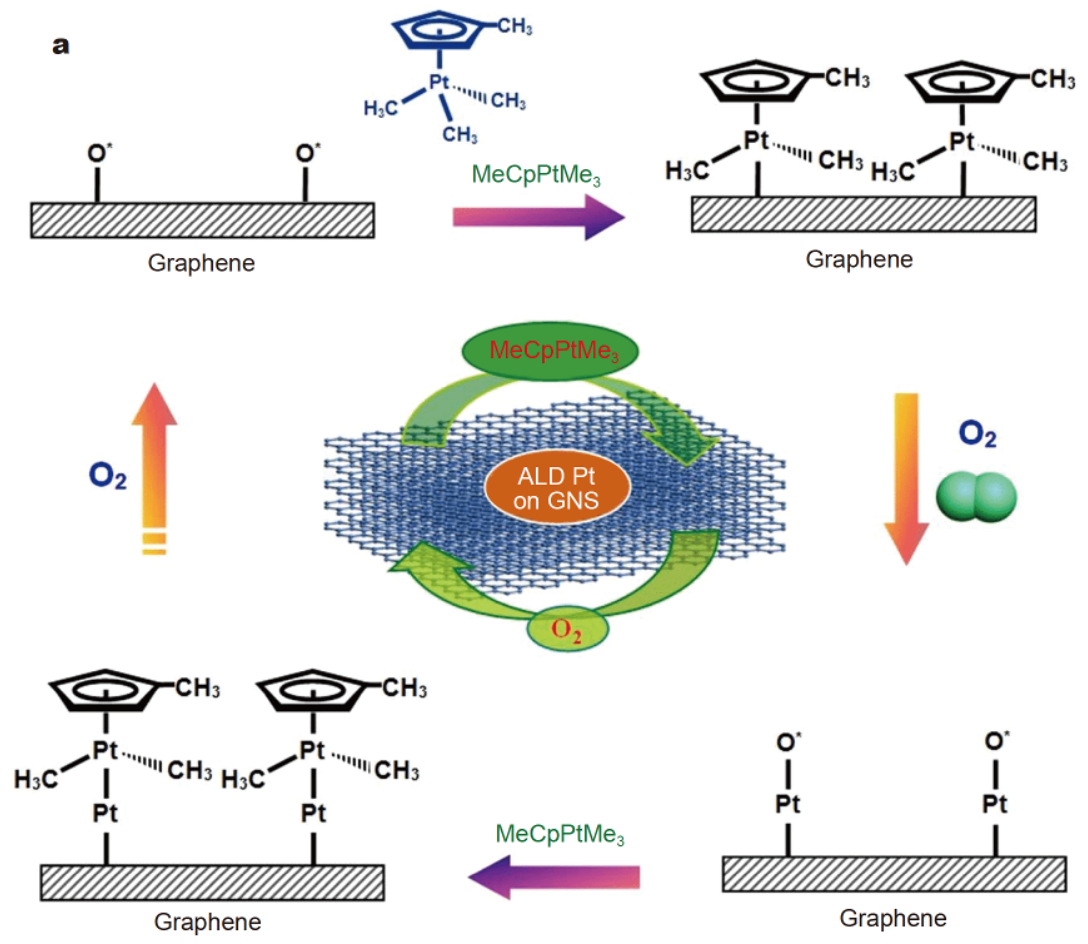
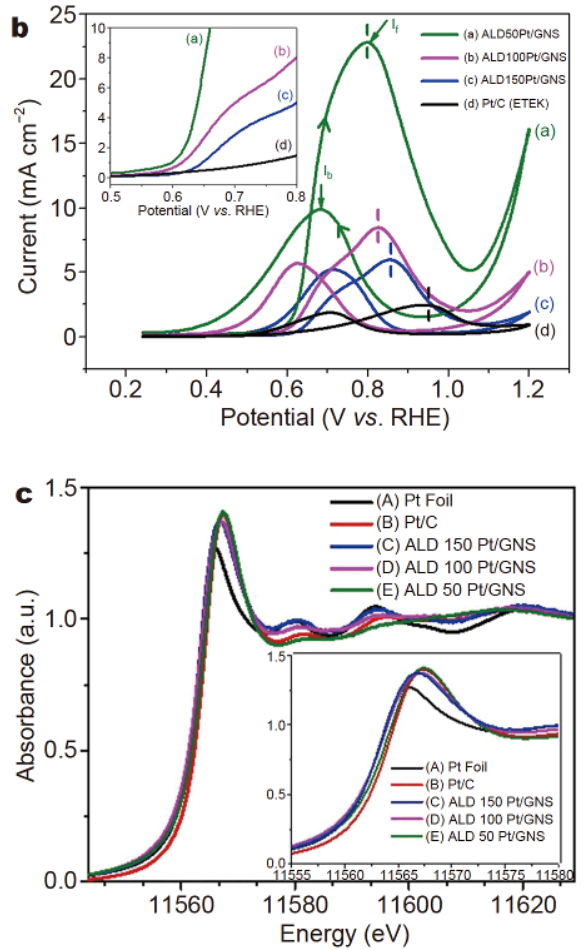

Figure 4 (a) Schematic diagrams of Pt ALD principle, (b) CV curves of methanol oxidation, (c) XANES spectra at Pt $\mathrm{L}_{3}$ edge. Reprinted with permission from Ref. [30], Copyright 2013, Nature Publishing Group.

$22.9 \mathrm{~mA} \mathrm{~cm}^{-2}$ by adopting cyclic voltammetry $(\mathrm{CV})$ and $\mathrm{X}$-ray absorption fine structure (XAFS) in MOR, which was 2.7 and 9.5 times that of 100ALD Pt/GNS and Pt/C catalysts, respectively (Fig. 4b, c). The excellent catalytic performance of Pt/GNS catalysts attributed to the isolated single Pt atoms and unique structure of graphene. It indicated that Pt/GNS catalysts had an excellent CO tolerance and adsorption rates. Above all, compared with commercial $\mathrm{Pt} / \mathrm{C}$ catalysts, the $\mathrm{Pt} / \mathrm{GNS}$ catalysts exhibited superior activity and durability in MOR and CO oxidation reaction.

Yan et al. [82] compounded stable dimeric $\mathrm{Pt}_{2} /$ graphene catalysts, with nucleation center with single $\mathrm{Pt}_{1}$ atoms deposited on graphene substrate, by ALD (Fig. 5a). The single Pt atoms had an optimum nucleation condition due to the unique properties and large specific area of graphene. Meanwhile, the dimeric $\mathrm{Pt}_{2} /$ graphene catalysts exhibited $2800 \mathrm{~mol}_{\mathrm{H} 2} \mathrm{~mol}_{\mathrm{Pt}}^{-1} \mathrm{~min}^{-1}$ at room temperature, which was 45 -fold higher than $\mathrm{Pt} /$ graphene catalysts in hydrolytic dehydrogenation of ammonia borane (Fig. 5b).

Yan et al. [32] prepared $\mathrm{Pd}_{1} /$ graphene catalysts through depositing single $\mathrm{Pd}$ atoms on the graphene surface by ALD. The catalysts exhibited $100 \%$ butene selectivity and
95\% conversion rate by aberration-corrected HAADFSTEM and XAFS, which demonstrated excellent durability in the continuous selective hydrogenation of 1,3butadiene reaction for $100 \mathrm{~h}$ without any change in activity and selectivity. Therefore, the $\mathrm{Pd}_{1} /$ graphene catalysts presented excellent application prospects in the selective 1,3-butadiene hydrogenation reaction.

Stambula et al. [48] compounded $\mathrm{Pt} / \mathrm{N}$-graphene catalysts by depositing single $\mathrm{Pt}$ atoms on $\mathrm{N}$-graphene surface via ALD, which exhibited outstanding catalytic performance. It provided a direction for the synthesis of large specific surface area catalysts in the proton exchange membrane fuel cell (PEMFC).

\section{Focused electron beam irradiation}

Robertson et al. [85] fabricated single atom Fe/graphene catalysts by irradiating graphene surface with the focused electron beam irradiation. The dopant single Fe atoms, embedded to graphene lattice, have caused the displacement of carbon atoms, which was important for designing the $\mathrm{Fe} /$ graphene catalysts with theoretical results.

\section{EG reduction}

EG reduction is a method for preparing metal/substrate 

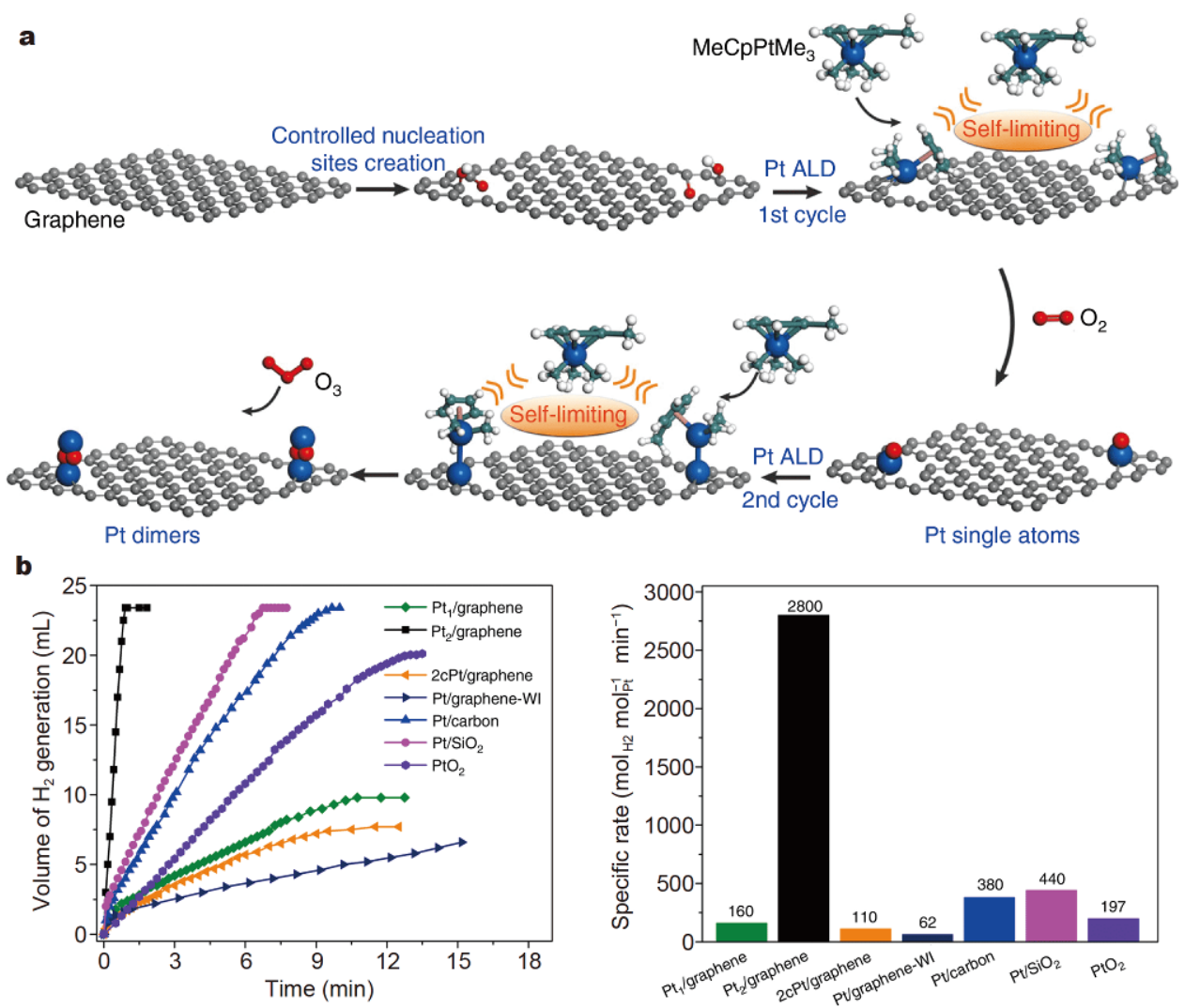

Figure 5 (a) Schematic diagrams of dimeric $\mathrm{Pt}_{2} /$ graphene catalysts, (b) catalytic activities of diverse Pt catalysts. Reprinted with permission from Ref. [82], Copyright 2017, Springer Nature.

electrocatalysts [95,96]. Shao et al. [95] deposited Pt nanoparticles on the poly(diallyldimethylammonium chloride) (PDDA) coated with graphene nanoplatelets (GNPs) by the ethylene glycol reduction method. The preparation processes included the following steps: first, GNPs were uniformly dispersed in the PDDA aqueous solution; second, PDDA-functionalized GNPs were added into the EG solution and stirred for $1 \mathrm{~h}$; and finally, the products were washed with deionized water and vacuum dried at $90^{\circ} \mathrm{C}$ for $3 \mathrm{~h}$. Compared with the traditional $\mathrm{Pt}$ nanoparticles supported on carbon nanotubes (Pt/CNT catalysts) or Pt/C catalysts, the Pt nanoparticles supported on graphene nanoplatelets (Pt/GNPs catalysts) exhibited excellent catalytic performance for oxygen reduction in fuel cells (Fig. 6).

\section{High-energy ball milling}

Deng et al. [41] prepared graphene-embedded $\mathrm{FeN}_{4}$ ( $\mathrm{FeN}_{4} / \mathrm{GN}, \mathrm{GN}$ represents nanosheet) catalysts with $\mathrm{FePc}$ and GN composites. The catalysts exhibited an excellent catalytic performance (conversion of $23.4 \%$ and yield of $18.7 \%)$ in the direct catalytic oxidation of benzene to phenol, and the conversion still maintained $8.3 \%$ at $0^{\circ} \mathrm{C}$ for $24 \mathrm{~h}$.

\section{Arc discharge}

Zhang et al. [86] prepared single $\mathrm{Nb}$ atoms supported on graphite ( $\mathrm{Nb}$ /graphite catalysts) by controlling the distance between niobium rod and carbon rod, and finally niobium atoms and carbon atoms were deposited at the same time. The experiment revealed that $\mathrm{Nb}$ /graphite catalysts enhanced the overall conductivity and prevented the agglomeration of single atoms. Theoretical calculations indicated that the $\mathrm{Nb}$ /graphite catalysts showed high activity and high stability in cathodic ORR.

\section{CHARACTERIZATION METHODS}

The advanced, accurate and efficient characterizations of SACs have attracted great attention in recent years. The main characterization methods of SACs include HAADFSTEM and XAFS.

\section{XAFS spectroscopy}

XAFS is an emerging technique developed with syn- 

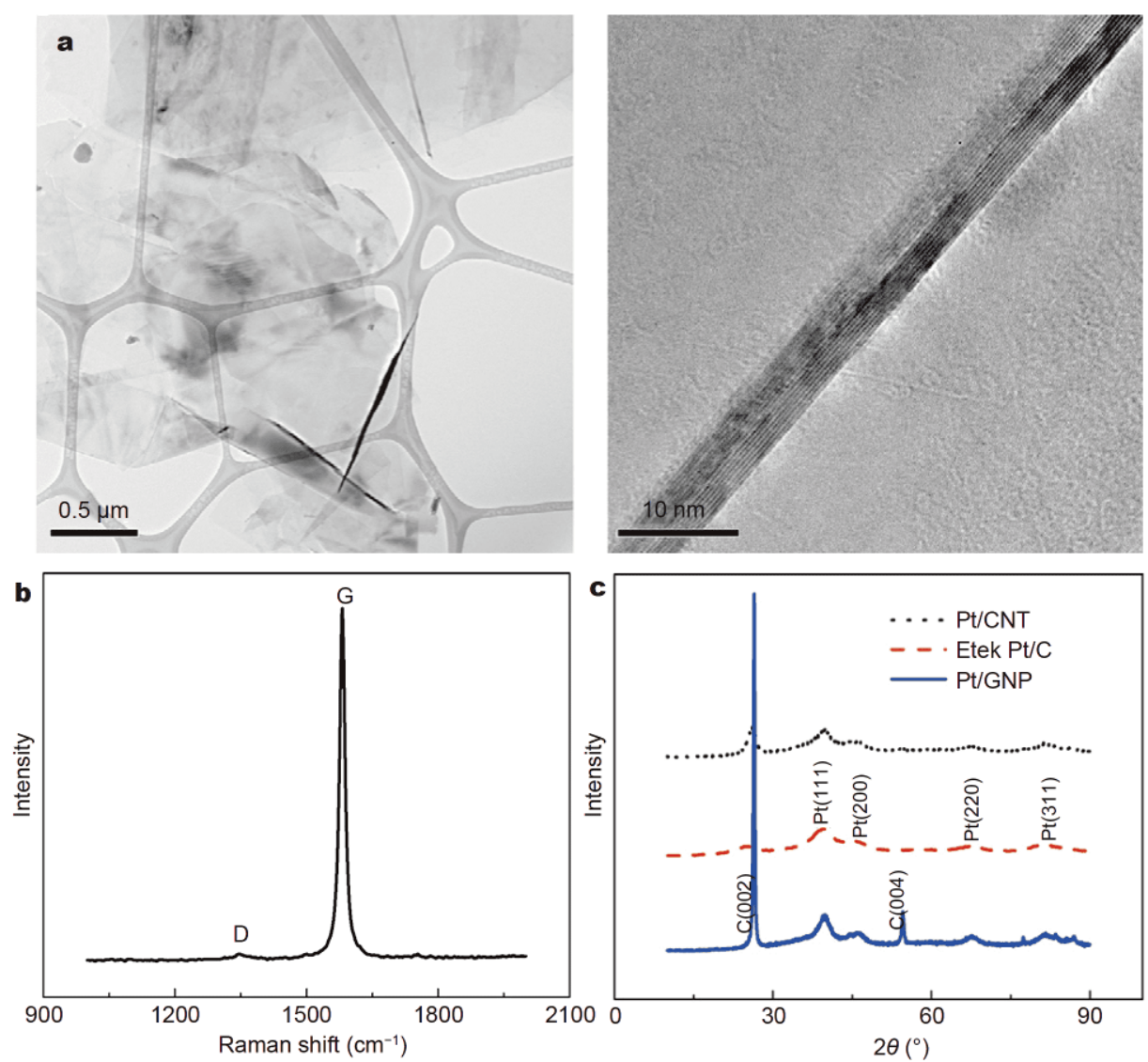

Figure 6 TEM images (a), Raman spectrum (b) and XRD patterns (c) of graphene nanoplatelets. Reprinted with permission from Ref. [95], Copyright 2010, Elsevier.

chrotron radiation, which is an important method for studying the localized atomic structure and electronic structure of materials.

As shown in Fig. 7 [97], the XAFS spectrometer consists of two parts, X-ray absorption near edge structure (XANES) and extended X-ray absorption fine structure (EXAFS). The energy range of EXAFS is about $50-100 \mathrm{eV}$, which is derived from the single-scattering effect of the inner-shell photoelectrons excited by X-rays. XANES contains energy ranges of less than $10 \mathrm{eV}$ and over $50 \mathrm{eV}$, which are mainly derived from the multiple scattering effects of inner-shell photoelectrons excited by $\mathrm{X}$-rays.

Sun et al. [30] prepared single atom Pt/graphene catalysts. It was difficult to find the Pt crystal phase by conventional XRD techniques due to the low Pt loading. Whereas, the singe Pt atoms could be characterized by XAFS. The $\mathrm{L}_{3}$-edge white-line intensity of single Pt atoms on the graphene surface was slightly different from that of $\mathrm{Pt} /$ carbon black. The $\mathrm{L}_{3}$-edge white-line intensity de-

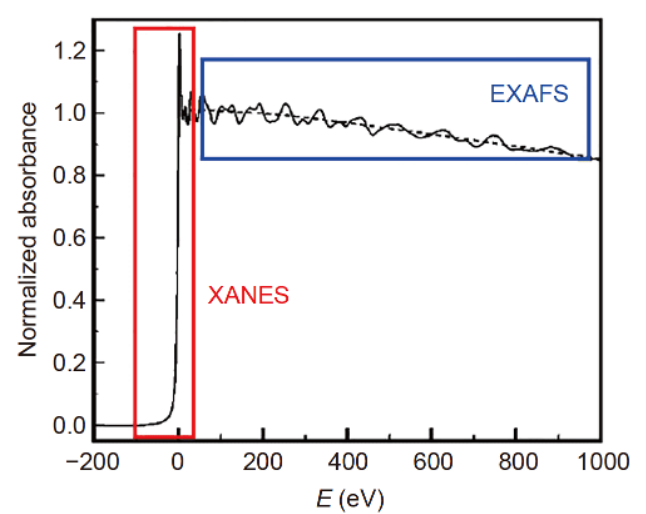

Figure $7 \mathrm{Pt} \mathrm{L}_{3}$-edge XAFS spectrum for platinum foil. Reprinted with permission from Ref. [97], Copyright 2000, Springer.

creased while the ALD deposition layer increased (50ALDPt/GNS > 100ALDPt/GNS >150ALDPt/GNS > Pt/ $\mathrm{C})$, in accord with the same order of $\mathrm{CO}$ tolerance and MOR. Therefore, the interfacial bonding force of Pt/GNS was stronger than that of $\mathrm{Pt} / \mathrm{C}$; meanwhile, the decrease 

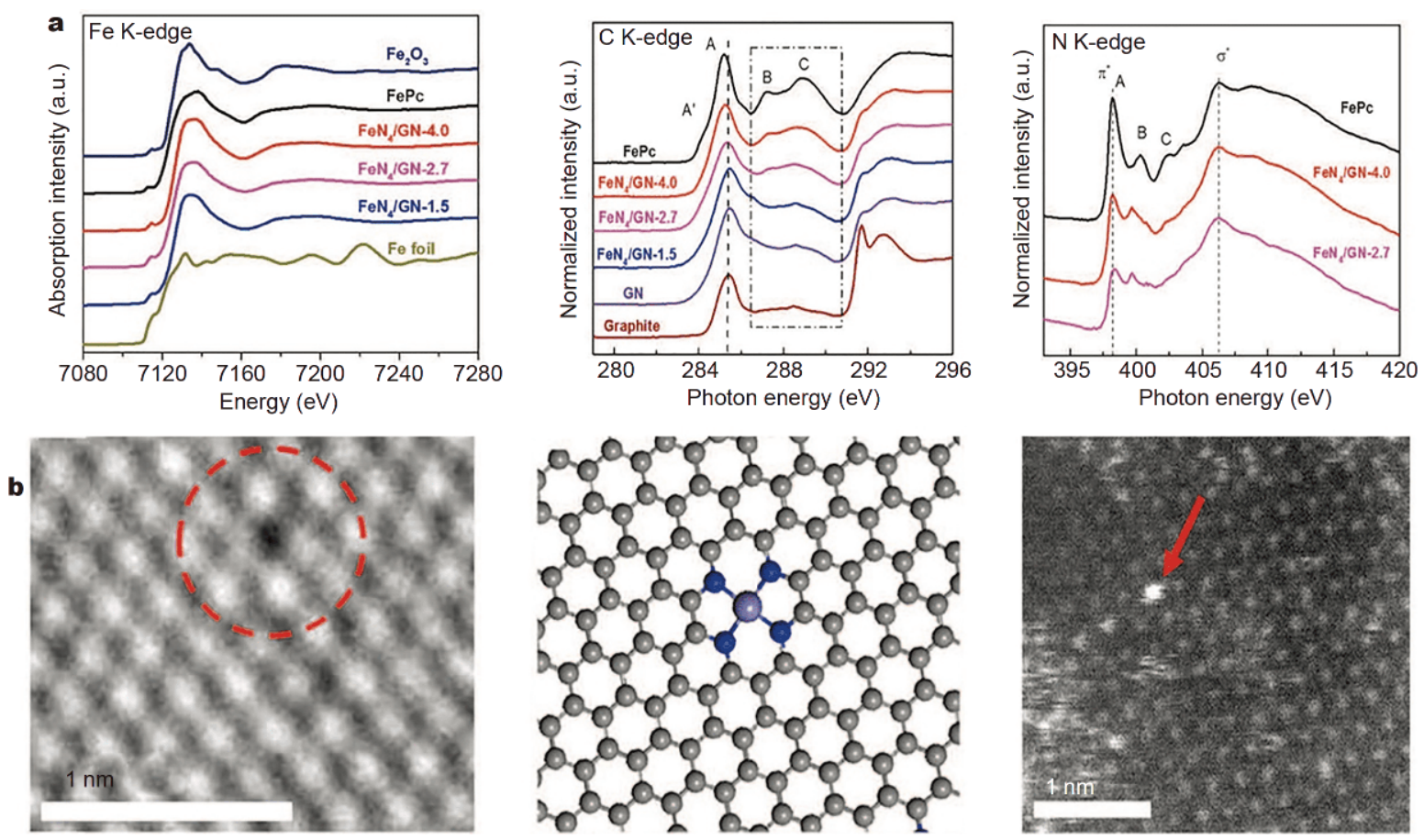

Figure 8 (a) Coordination structure and valence state of $\mathrm{FeN}_{4} / \mathrm{GN}$ catalysts, (b) morphology analysis of $\mathrm{FeN}_{4} / \mathrm{GN}$ catalyst. Reprinted with permission from Ref. [41], Copyright 2015, American Association for the Advancement of Science.

of deposition times could effectively increase the whiteline intensity.

Yan et al. [32] observed the isolated single Pd atoms dispersed on graphene by XANES and XAFS. The XANES spectra of the Pd K-edge indicated that the isolated Pd atoms on graphene surface may be zero valence or +2 valence states. The EXAFS spectra of the Pd K-edge indicated that the coordination environment around the Pd atom exhibited a highly distorted structure, which showed accurate quantitative XAFS contributing to the characterization of the deposited single atoms on graphene.

Deng et al. [41] revealed the coordination structure and valence state of single $\mathrm{Fe}$ atoms in the $\mathrm{FeN}_{4} / \mathrm{GN}$ catalysts by XAFS (Fig. 8a). The near-edge structure of $\mathrm{FeN}_{4} / \mathrm{GN}$ catalysts was similar to that of original FePc by the Fe Kedge of XANES. The number of $\mathrm{C}=\mathrm{N}$ bonding decreased significantly, which indicated that the $\mathrm{FeN}_{4}$ structure remained stable (Fig. 8b).

\section{Aberration-corrected HADDF-STEM}

The HAADF-STEM can improve the resolution to the sub-angstrom level and eliminate the spherical phase difference in the transmission system. The single atoms or clusters can be observed as a light spot by HAADF, so that the chemical composition information of the atomic resolution can be obtained [98].

As shown in Fig. 9, in the range of $\theta_{3}$, the signals are primarily transmitted electron beams and scattering electrons. In the range of $\theta_{2}$, the received signals are Bragg scattering electrons. If the received signals are primarily incoherent scattering electrons with high-angle in the $\theta_{1}$ range, the HAADF image can be obtained. The light spot in the image always correlates to the column of atoms [99]. Therefore, HAADF-STEM plays a decisive role in materials science, chemistry, physics and other fields.

Yan's group [32] discovered the single atom $\mathrm{Pd}_{1} /$ graphene catalysts with high activity, superior selectivity of butene and stability under continuous reaction. They demonstrated by HAADF-STEM that the isolated single $\mathrm{Pd}$ atoms were randomly deposited on the graphene surface (Fig. 10a). Single Pd atoms presented a special steric effect when the annealing temperature was $1050^{\circ} \mathrm{C}$, which was a crucial reason for excellent catalytic performance of $\mathrm{Pd}_{1} /$ graphene catalysts (Fig. 10c).

Stambula et al. [48] observed isolated single Pt atoms and clusters on $\mathrm{N}$-graphene surface by HAADF-STEM. Single Pt atoms were mainly stacked on the graphene edges. Only a small number of single Pt atoms were 


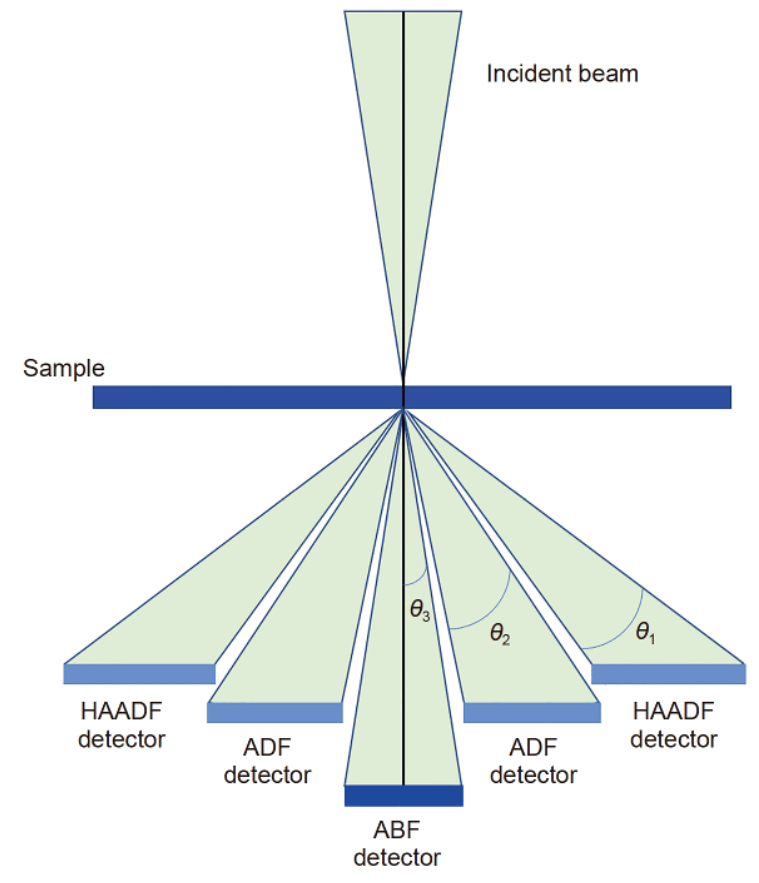

Figure 9 STEM detector distribution diagram.

distributed in the center of graphene surface. It was proved that the Pt element stacked on N-graphene existed as single atoms or clusters through HAADF-STEM.

\section{ADVANTAGES OF GRAPHENE- SUPPORTED METAL SACs}

\section{High activity}

The catalytic efficiency of metal solid-supported catalysts will increase in order of magnitude when the size reaches to single atom scale. Qiao et al. [5] prepared single atom $\mathrm{Pt}_{1} / \mathrm{FeO}_{x}$ catalysts with 2-3 orders of magnitude higher catalytic performance than conventional catalysts. In recent years, the preparation techniques of high-quality graphene have been improved, which is frequently used as solid-support catalytic substrate. On account of the large specific area (approx. $2630 \mathrm{~m}^{2} \mathrm{~g}^{-1}$ ), graphene can reduce the surface free energy and prevent agglomeration of single atoms. Yang et al. [88] also synthesized single atom $\mathrm{Ni} / \mathrm{N}$-graphene catalysts, in which single $\mathrm{Ni}$ atoms were adopted as active metals. Fig. 11a, b show the scanning electron microscopy (SEM), atomic force microscopy (AFM) and TEM images of single atom Ni/Ngraphene catalysts. The exchange current density and turnover frequency (TOF) were an order of magnitude higher than the traditional catalysts (Fig. 11c, d). The high $\mathrm{CO}_{2}$ reduction activity resulted from the large specific surface area of the graphene substrate, which led to the distribution of the single atom $\mathrm{Ni}$ on the surface of graphene and the formation of $\mathrm{Ni}-\mathrm{C}$ bonds, and finally the
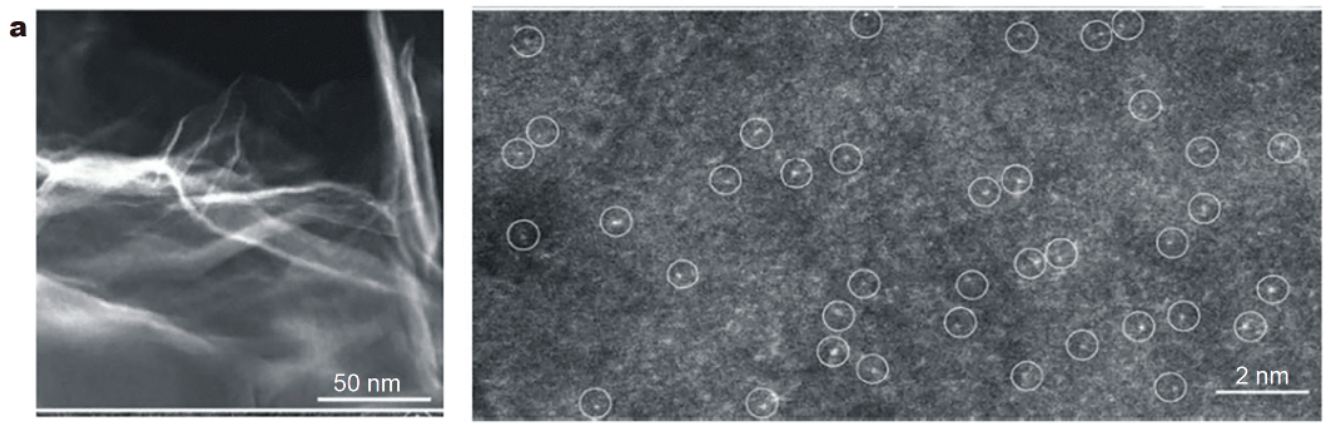

b

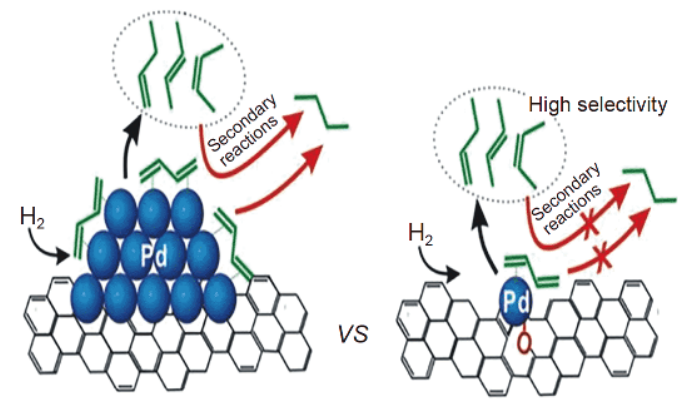

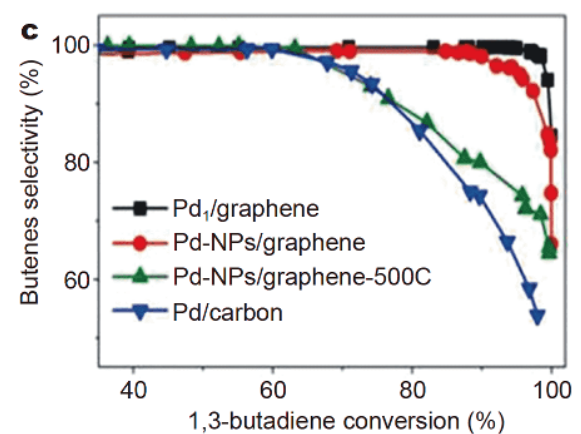

Figure 10 (a) HAADF-STEM images of $\mathrm{Pd}_{1} /$ graphene, (b) schematic diagrams of butene selectivity on $\mathrm{Pd}_{1} /$ graphene catalyst, (c) catalytic capabilities of various samples. Reprinted with permission from Ref. [32], Copyright 2015, American Chemical Society. 

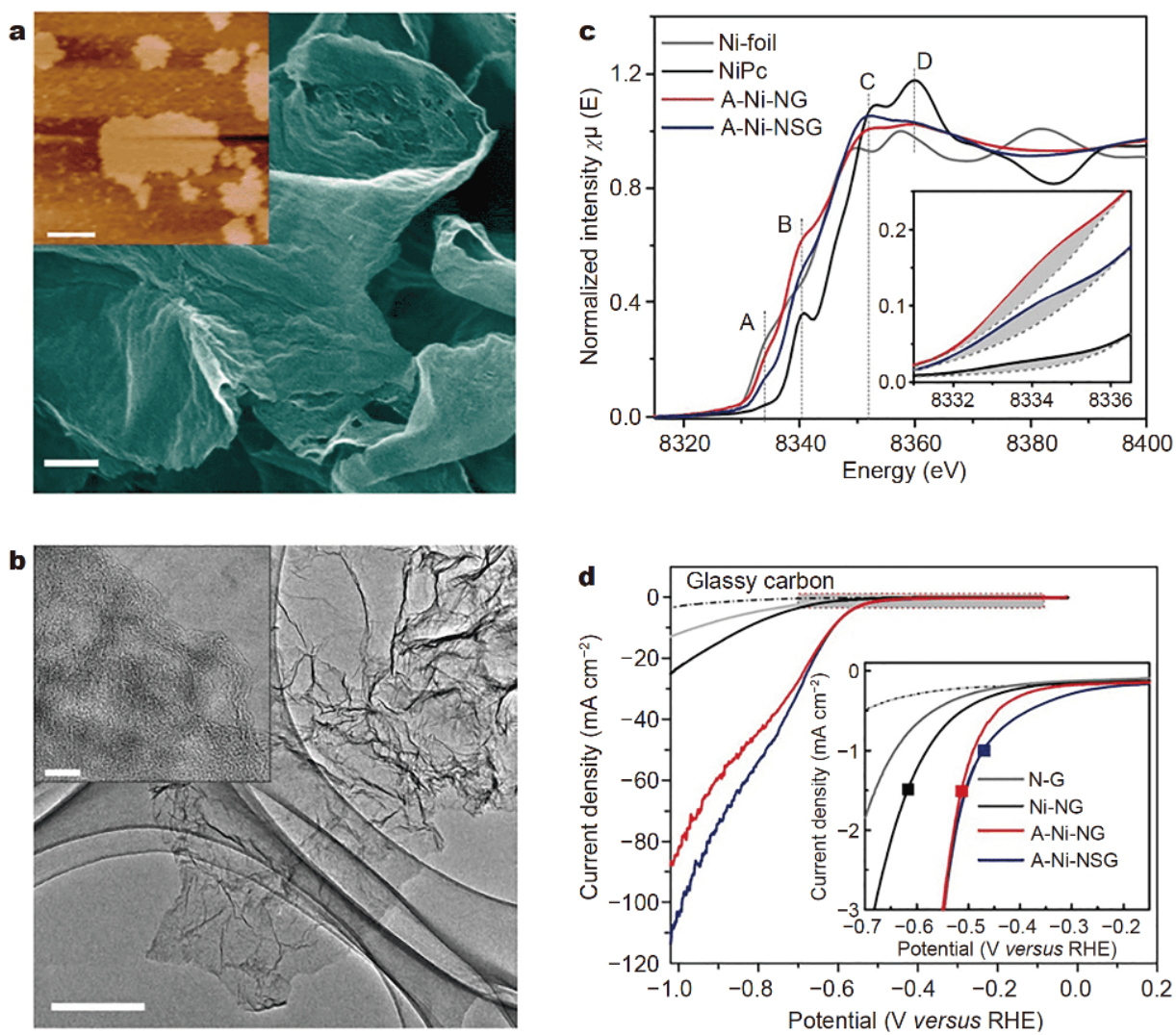

Figure 11 (a) SEM and AFM images of single atom Ni-graphene catalyst, (b) TEM image of Ni-graphene catalyst, (c) electronic states of Ni atom in the Ni-graphene catalysts, (d) $\mathrm{CO}_{2}$ reduction in aqueous solution. Reprinted with permission from Ref. [88], Copyright 2018, Springer Nature.

redistribution of electrons in the $\mathrm{Ni} 3 \mathrm{~d}$ orbital. Ta et al. [31] compounded the single $\mathrm{Cr}$ atoms supported on graphene (Cr/graphene catalysts). Graphene substrates with a single atomic layer thickness played a decisive role and can accurately characterize single atomic $\mathrm{Cr}$ under TEM. The current density of the SACs was several orders of magnitude higher than that of commercial catalysts. Compared with commercial Pt/C catalysts, Sun et al. [30] prepared the single atom $\mathrm{Pt} /$ graphene catalysts with excellent performance in MOR and CO oxidation, which was attributed to the distinctive properties of graphene substrate (high surface area, high conductivity and unique surface structure), and ultimately improved utilization efficiency of single Pt atoms.

\section{High stability}

For traditional industrial catalysts, the stability and catalytic activity will reduce in chemical reaction for hundreds of hours, resulting in the deactivation of the catalysts. However, the SACs cannot be easily agglomerated and inactivated due to the low-loading of single metal atoms and unique graphene structure. Deng et al.
[41] synthesized single Fe atoms supported on graphene, which revealed high stability in the catalytic reaction of benzene to phenol. The conversion yield of phenol still reached $8.3 \%$ over $24 \mathrm{~h}$. Due to its unique structure and electronic properties, graphene is a good carrier to limit metallic coordinatively unsaturated iron atoms in the matrix. Yang et al. [88] fabricated the single atom $\mathrm{Ni} / \mathrm{N}$ graphene catalysts (forming $\mathrm{Ni}-\mathrm{C}$ bonds), which could retain up to $98 \%$ activity in the $\mathrm{CO}$ formation current density after a $100 \mathrm{~h}$ continuous reaction. Yan et al. [32] prepared single atom $\mathrm{Pd}_{1} /$ graphene catalysts that revealed superior stability in hydrogenation reaction of 1,3-butadiene, which exhibited $100 \%$ butene selectivity at $95 \%$ conversion rate over $100 \mathrm{~h}$. The unique structure of graphene ensured a highly distorted coordination around $\mathrm{Pd}$ atoms, and formed $\mathrm{Pd}-\mathrm{C}$ coordination and $\mathrm{Pd}-\mathrm{O}$ coordination. Fei et al. [43] synthesized single atom $\mathrm{Co} / \mathrm{N}-$ graphene catalysts. The $\mathrm{Co} / \mathrm{N}$-graphene catalysts exhibited good stability according to the current density of the cathodic polarization curve for 1000 cycles, which was attributed to the high catalyst loading, tolerance of harsh reactions and acceleration of electron transfer of gra- 
phene substrate and $\mathrm{Co}-\mathrm{C}$ path.

\section{High selectivity}

The noble metal atomic radii of SACs are in the range of 1-1.5 $\AA$; meanwhile, the minimum size and low loading determine the isolated catalytic active sites. Zhao et al. [100] prepared metal-organic framework-derived catalysts with improved ORR selectivity. Wang et al. [87] predicted that single $\mathrm{Si}$ atoms would exhibit superior activity and ultra-high selectivity based on DFT calculations. High-selectivity single atom Si/graphene catalysts could open micropores on the graphene surface and maintain the integrity of graphene, which could contribute to novel electronic and spintronic properties of graphene nanostructures and the better design for preparation of SACs. Yan et al. [32] introduced single atom $\mathrm{Pd}_{1} /$ graphene that exhibited $100 \%$ selectivity of 1,3 -butadiene and $70 \%$ selectivity of 1-butene, which provided a new possibility for improving the selectivity of hydrogenation reaction.

Graphene-supported metal SACs have exhibited excellent catalytic performance in many catalytic reactions. The isolated and efficient single metal atoms anchored on the graphene sheet present a stable structure. Meanwhile, graphene-supported metal SACs have exhibited high selectivity in ORR reactions and revealed excellent toxic tolerance and stability in $\mathrm{CO}$ oxidation reactions. Graphene-supported metal SACs will provide a new direction to design novel and more efficient catalysts for green catalysis.

\section{APPLICATIONS OF GRAPHENE- SUPPORTED METAL SACs}

\section{CO oxidation reaction}

A majority of $\mathrm{CO}$ is derived from fossil fuel combustion emissions, vehicle exhaust emissions and chemical industry exhaust gas, which seriously influence our environment. High-efficiency oxidation of $\mathrm{CO}$ at low temperature is the most direct, inexpensive and simple method to effectively reduce $\mathrm{CO}$ pollution. Qiao et al. [5] firstly obtained $\mathrm{Pt}_{1} / \mathrm{FeO}_{x}$ catalysts that exhibited high activity in $\mathrm{CO}$ oxidation. The theoretical binding energy of adsorbed $\mathrm{CO}$ on a single Pt atom was $1.27 \mathrm{eV}$, which was much lower than the calculated value of Pt cluster. In the $\mathrm{CO}_{\mathrm{ad}}+\mathrm{O}-\mathrm{O}_{\mathrm{ad}} \rightarrow \mathrm{CO}_{2}+\mathrm{O}_{\mathrm{ad}}$ reaction process, the active barrier calculation was $0.49 \mathrm{eV}$. When the second $\mathrm{CO}$ molecule was adsorbed on the $\mathrm{Pt}$ atom, the active barrier was $0.79 \mathrm{eV}$ according to the $\mathrm{CO}_{\mathrm{ad}}+\mathrm{O}_{\mathrm{ad}} \rightarrow \mathrm{CO}_{2}+$ $\mathrm{O}_{\text {vac }}$ reaction process. Therefore, the low barriers ensured the thermodynamic and kinetic reaction equilibrium of $\mathrm{Pt}_{1} / \mathrm{FeO}_{x}$ catalysts. From then on, graphene-supported metal SACs have made an important progress in $\mathrm{CO}$ removal.

Wu et al. [38] calculated the stability and CO oxidation behavior of single $\mathrm{Fe}$ atom catalysts. In the Eley-Rideal mechanism, $\mathrm{CO}$ oxidation involves the following two reactions: $\mathrm{O}_{2(\mathrm{ad})}+\mathrm{CO}_{(\mathrm{gas})} \rightarrow \mathrm{O}_{(\mathrm{ad})}+\mathrm{O}_{(\mathrm{ad})}+\mathrm{CO}_{(\mathrm{gas})} \rightarrow \mathrm{O}_{(\mathrm{ad})}$ $+\mathrm{CO}_{2 \text { (gas) }}, \mathrm{CO}_{\text {(gas) }}+\mathrm{O}_{(\mathrm{ad})} \rightarrow \mathrm{CO}_{2(\mathrm{gas})}$. Compared with traditional catalysts, the energy barrier of novel single $\mathrm{Fe}$ atom catalysts was only $0.21 \mathrm{eV}$ by the theoretical calculation, which was due to $\mathrm{Fe}-\mathrm{C}$ bonds, leading to the high activity and stability of the single Fe atom catalysts in $\mathrm{CO}$ oxidation.

Liu et al. [39] obtained the Pt-embedded/graphene catalysts on graphene substrate, which exhibited high catalytic efficiency of $\mathrm{CO}$ oxidation at low temperature due to the breaking of the $\mathrm{O}-\mathrm{O}$ bond and the formation of new C-O bonds (Fig. 12). Zhang et al. [40] prepared the $\mathrm{Pt} / \mathrm{N}$-graphene catalysts (forming $\mathrm{Pt}-\mathrm{C}$ bond), which also showed excellent activity and stability in $\mathrm{CO}$ oxidation at low temperature through $2 \mathrm{CO}+\mathrm{O}_{2} \rightarrow$ OCO$\mathrm{OCO} \rightarrow 2 \mathrm{CO}_{2}$ mechanism.

\section{Oxidation of benzene to phenol}

Phenol, as an important organic petrochemical raw material, is widely used in the fields of synthetic rubber $[101,102]$ and petroleum refining [103,104]. Industrial synthetic phenol is confronted with several problems, such as long reaction time, heavy pollution and high cost $[105,106]$. The oxidizing agents include $\mathrm{H}_{2} \mathrm{O}_{2}$ and $\mathrm{N}_{2} \mathrm{O}$. The equation for the heterogeneous catalysis system of the $\mathrm{H}_{2} \mathrm{O}_{2}$ is listed below:

$\mathrm{C}_{6} \mathrm{H}_{6}+\mathrm{H}_{2} \mathrm{O}_{2} \stackrel{\text { catalyst }}{\longrightarrow} \mathrm{C}_{6} \mathrm{H}_{5} \mathrm{OH}+\mathrm{H}_{2} \mathrm{O}$,

and the equations for the $\mathrm{N}_{2} \mathrm{O}$ system are as follows [107]: $\mathrm{N}_{2} \mathrm{O}+\mathrm{e}^{-}$(from catalyst) $\rightarrow \mathrm{N}_{2}+\mathrm{O}^{-}$;

$\mathrm{C}_{6} \mathrm{H}_{6}+\mathrm{O}^{-} \rightarrow \mathrm{C}_{6} \mathrm{H}_{5} \cdot+\mathrm{OH}^{-}$

$\rightarrow \mathrm{C}_{6} \mathrm{H}_{5} \mathrm{OH}+\mathrm{e}^{-}$(to catalyst).

Both catalytic processes are environment-friendly. However, direct oxidation of benzene to phenol in industry requires highly active catalysts and long reaction path. Deng et al. [41] compounded the $\mathrm{FeN}_{4} / \mathrm{GN}$ catalysts by depositing single $\mathrm{Fe}$ atoms on graphene. The results proved direct catalytic oxidation of benzene to phenol with high efficiency due to $\mathrm{Fe}=\mathrm{O}$ intermediate. The conversion and yield could reach $23.4 \%$ and $18.7 \%$ at room temperature, respectively. Furthermore, the conversion could still maintain $8.3 \%$ after $24 \mathrm{~h}$, which was 


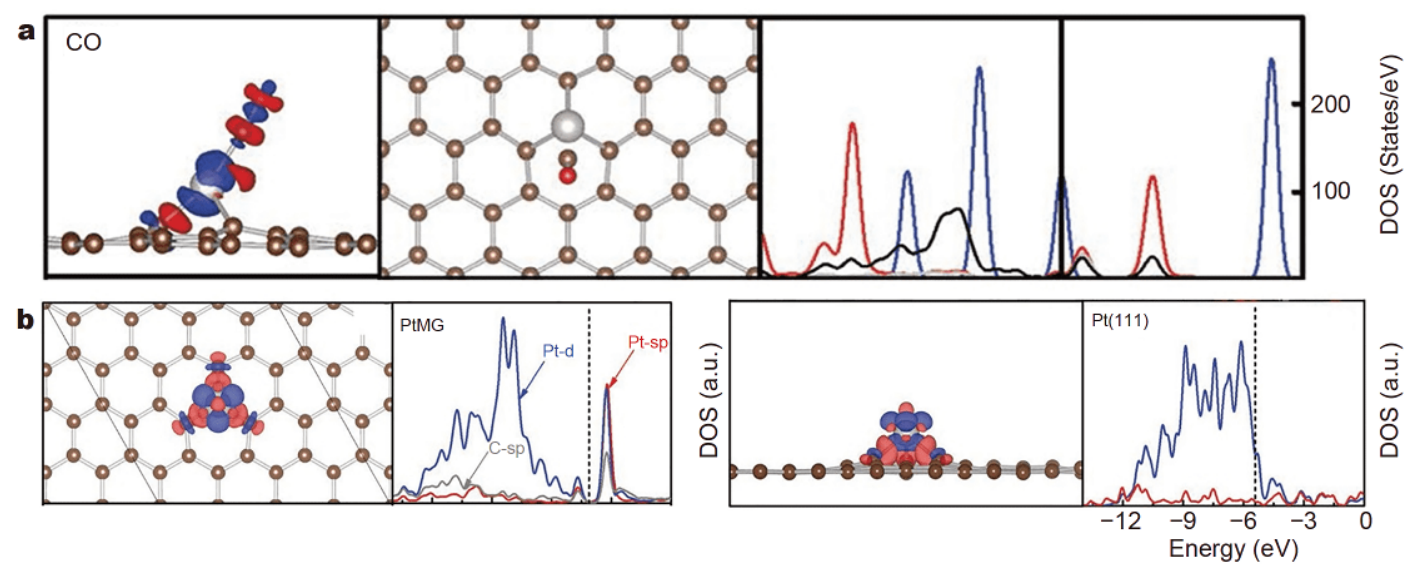

Figure 12 (a) The plausible theoretical calculation results for CO adsorption on PtMG, (b) the contour plot of PtMG, DOS of PtMG and Pt (111) surface. Reprinted with permission from Ref. [39], Copyright 2014, Royal Society of Chemistry.

superior to traditional catalysts (homogeneous precious metal catalysts). Graphene-supported metal SACs are expected to solve the problems absolutely of benzene to phenol at room temperature.

\section{HER}

Hydrogen is an energy carrier with high energy density and superior heat release properties which render it attractive as a clean and carbon-free fuel [108-110]. Water electrolysis plants in industry require highly active and stable catalysts, which is relatively difficult in $\operatorname{HER}\left(2 \mathrm{H}^{+}+\right.$ $2 \mathrm{e}^{-} \rightarrow \mathrm{H}_{2}$ ) by large scale. Yan et al. [82] fabricated single atom $\mathrm{Pt}_{2} /$ graphene catalysts (forming $\mathrm{Pt}-\mathrm{C}, \mathrm{Pt}-\mathrm{Pt}$ and $\mathrm{Pt}-\mathrm{O}$ bonds). The specific rate of dimeric $\mathrm{Pt}_{2} /$ graphene catalysts was 45 -fold higher than Pt nanoparticle/graphene catalysts in hydrolytic dehydrogenation of ammonia borane. Fei et al. [43] prepared single atom $\mathrm{Co} / \mathrm{N}$ graphene catalysts (forming Co-C path), which exhibited superior catalytic performance in water electrolysis plant of hydrogen. The catalysts maintained a high activity even for low over potential $(30 \mathrm{mV})$. Single atom $\mathrm{Co} / \mathrm{N}$-graphene catalysts with high adaptability of HER have the potential to replace expensive Pt catalysts in the future.

\section{MOR}

Formaldehyde is widely used in chemical industry, such as for wood, textile and aczoiling applications [111]. The commonly used method for the preparation of formaldehyde is direct oxidation with precious metal catalysts such as $\mathrm{Pt}$

$2 \mathrm{CH}_{3} \mathrm{OH}+\mathrm{O}_{2} \stackrel{\text { catalyst }}{\longrightarrow} 2 \mathrm{H}_{2} \mathrm{O}+2 \mathrm{HCHO}$

however, the catalytic efficiency is very limited [112]. Yoo et al. [44] synthesized the Pt/GNS electrocatalysts which exhibited extraordinary activity for MOR (existing Pt-C bonds). Fig. 13a, $c$ show the TEM image, histogram and HAADF-STEM image of Pt/GNS. Fig. 13b shows the current-potential curves for MOR on Pt/carbon black, Pt/ GNS and $\mathrm{Pt} / \mathrm{Ru}$-carbon black, which indicates excellent catalytic activity for MOR on Pt/GNS. Li et al. [45] obtained the $\mathrm{Pt} /$ chemically converted graphene (Pt/CCG) catalysts by depositing Pt nanoparticles on RGO. The electrochemically active specific area was $36.27 \mathrm{~m}^{2} \mathrm{~g}^{-1}$, superior to single $\mathrm{Pt}$ atoms supported on multi-walled carbon nanotubes catalysts for $34.43 \mathrm{~m}^{2} \mathrm{~g}^{-1}$. The Pt/CCG catalysts exhibited good durability in MOR due to functional groups like $-\mathrm{COOH}$ and $-\mathrm{OH}$ groups. Zhao et al. [46] reported the Pd/polypyrrole-graphene (Pd/PPy-graphene) catalysts by depositing Pd nanoparticle on PPyfunctionalized graphene, which showed a catalytic performance superior to traditional catalysts in the MOR.

\section{ORR}

Fuel cell is a new-generation efficient and green device in the 21st century [113-115]. The ORR reaction occurs when oxygen is reduced at the cathode of the fuel cell. The half-cell reaction is as follows: $\mathrm{O}_{2}+4 \mathrm{H}^{+}+4 \mathrm{e}^{-} \rightarrow$ $2 \mathrm{H}_{2} \mathrm{O} ; \mathrm{O}_{2}+2 \mathrm{H}^{+}+2 \mathrm{e}^{-} \rightarrow \mathrm{H}_{2} \mathrm{O}_{2}$.

The chemical formula demonstrates the overall process of the ORR of the catalyst surface, including the ORR to directly generate $\mathrm{H}_{2} \mathrm{O}$ through an ideal four-electron pathway, or the formation of $\mathrm{H}_{2} \mathrm{O}_{2}$ intermediate through an undesirable two-electron pathway. However, the high cost of the traditional Pt catalysts limits large-scale industrial applications [56,116,117]. Lefèvre et al. [47] produced microporous carbon-supported iron-based 

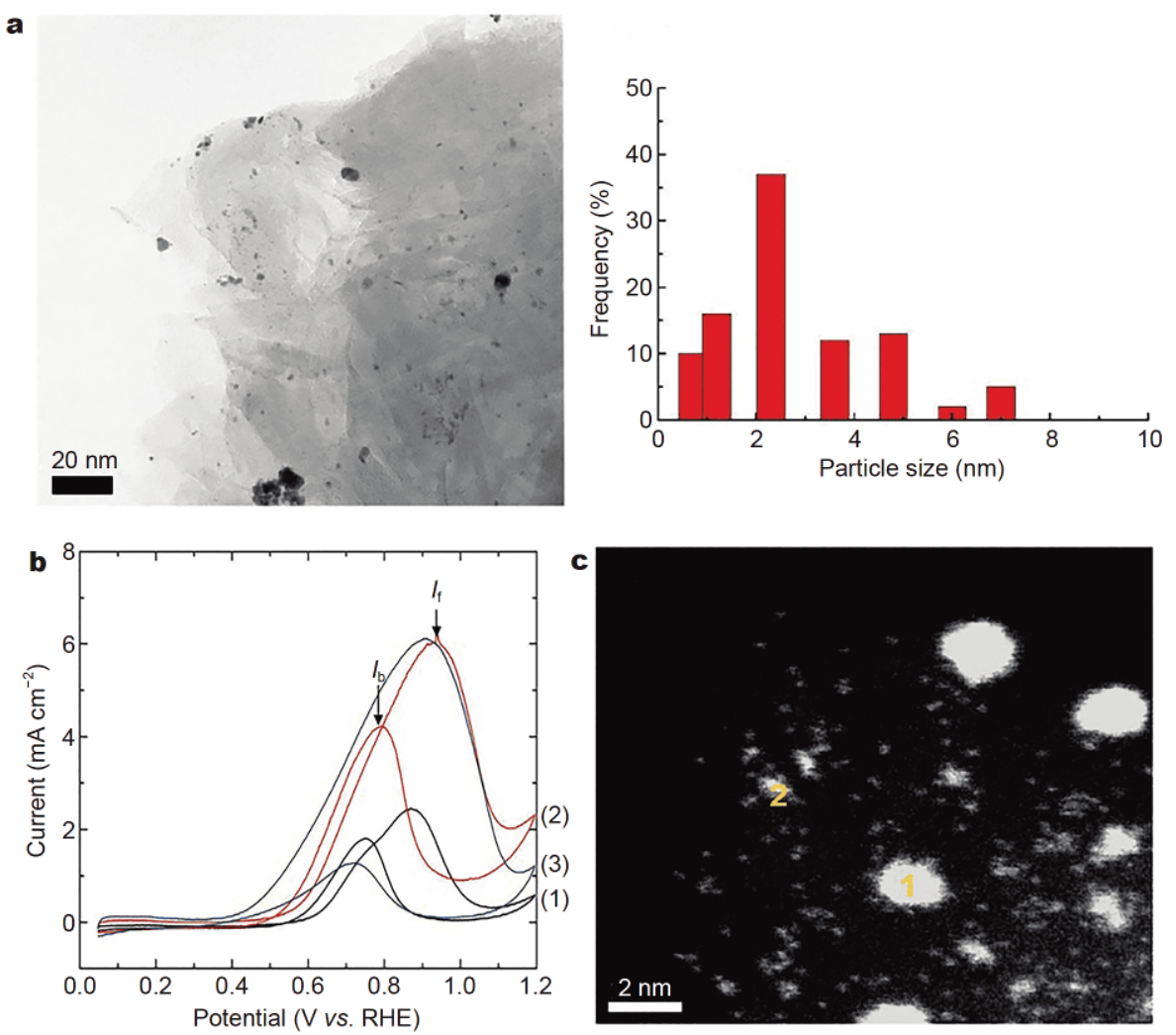

Figure 13 (a) TEM images and histogram of Pt/GNS; (b) current-potential curves for MOR on (1) Pt/carbon black, (2) Pt/GNS and (3) Pt/Ru-carbon black; (c) HAADF-STEM image of Pt/GNS. Reprinted with permission from Ref. [44], Copyright 2009, American Chemical Society.

catalysts, whose cathode current density could be comparable to that of platinum. This work provided a new direction of iron-based catalysts for ORR in polymer electrolyte membrane fuel cells. Wan et al. [118] established the connection between electrocatalysis and SAC. Compared with conventional 2D planar catalysts, the newly designed non-planar coordinated single atom cobalt had lower energy levels in $3 \mathrm{~d}$ orbital. The as-prepared single atom cobalt sites extremely improved the catalytic activity and selectivity in the ORR, which could be applied in the field of electrocatalysis. Graphene-supported SACs could not only present enhanced stability and durability for ORR, but also exhibit good oxygen adsorption and activation. Stambula et al. [48] prepared Pt/ $\mathrm{N}$-graphene catalysts by depositing single $\mathrm{Pt}$ atoms on $\mathrm{N}$ graphene surface (forming Pt-C bond). These catalysts prevented agglomeration due to the large number of $\mathrm{Pt}$ active sites. Compared with carbon black supported Pt nanoparticles, $\mathrm{Pt} / \mathrm{N}$-graphene catalysts could achieve enhanced catalytic efficiency in ORR and solve the problems in industrialization of PEMFC. Shao et al. [95] prepared Pt/PDDA-GNPs catalysts with outstanding catalytic per- formance (existing Pt-C interaction). The catalytic efficiency of the Pt/PDDA-GNPs catalysts was 3-fold improved compared with $\mathrm{Pt} / \mathrm{C}$ catalysts, which could gradually replace traditional catalysts on an industrial scale.

\section{Hydrogenation}

Selective hydrogenation of acetylene gas is an important step to purify olefin and obtain butadiene. The activity of precious metal Pd catalysts is degraded under high conversion conditions. Yan et al. [32] prepared $\mathrm{Pd}_{1} /$ graphene catalysts by depositing single $\mathrm{Pd}$ atoms on graphene surface (forming $\mathrm{Pd}-\mathrm{C}$ coordination and $\mathrm{Pd}-\mathrm{O}$ coordination). The $\mathrm{Pd}_{1} /$ graphene catalysts exhibited $100 \%$ butene selectivity and $95 \%$ conversion rate than conventional catalysts in selective hydrogenation of 1,3-butadiene

$\mathrm{C}_{4} \mathrm{H}_{6}+\mathrm{H}_{2} \stackrel{\text { catalyst }}{\longrightarrow} \mathrm{C}_{4} \mathrm{H}_{8}$.

Nie et al. [51] fabricated Pd nanoparticles supported on $\mathrm{N}$-doped RGO (Pd/N-RGO catalysts) by depositing Pd nanoparticle on $\mathrm{N}-\mathrm{RGO}$ surface (forming $\mathrm{C}=\mathrm{C}$ and $\mathrm{C}-\mathrm{N}$ 
bonds). The characterization exhibited high activity and selectivity of Pd/N-RGO catalysts in hydrogenation of phenol to cyclohexanone

$2 \mathrm{C}_{6} \mathrm{H}_{5} \mathrm{OH}+5 \mathrm{H}_{2} \stackrel{\text { Pd/N-RGO }}{\longrightarrow} \mathrm{C}_{6} \mathrm{H}_{10} \mathrm{O}+\mathrm{C}_{6} \mathrm{H}_{11} \mathrm{OH}$.

Above all, it is indicated that graphene-supported metal SACs will play an important role in selective hydrogenation reactions.

\section{Photoelectrocatalysis}

In recent years, $\mathrm{CO}_{2}$ concentration in the atmosphere constantly increases because of the large amount of fossil energy consumption, thus photoelectrocatalysis of $\mathrm{CO}_{2}$ reduction has become an important research direction. Cheng et al. [55] combined the Pt-modified RGO (PtRGO) and Pt-modified $\mathrm{TiO}_{2}$ nanotubes (Pt-TNT) with cathode and photoanode catalysts (existing $\mathrm{C}-\mathrm{O}, \mathrm{C}=\mathrm{O}$ and $\mathrm{O}=\mathrm{C}-\mathrm{O}$ bonds). The liquid product generation rate $\left(\mathrm{CH}_{3} \mathrm{OH}, \mathrm{C}_{2} \mathrm{H}_{5} \mathrm{OH}, \mathrm{HCOOH}\right.$, and $\left.\mathrm{CH}_{3} \mathrm{COOH}\right)$ of approximately $600 \mathrm{nmol} \mathrm{h}^{-1} \mathrm{~cm}^{-2}$ and carbon atom conversion rate of $1130 \mathrm{nmol} \mathrm{h}^{-1} \mathrm{~cm}^{-2}$ were demonstrated $\left(\mathrm{CO}_{2}+2 \mathrm{H}^{+}+2 \mathrm{e}^{-} \rightarrow \mathrm{CO}+\mathrm{H}_{2} \mathrm{O} ; \mathrm{CO}_{2}+2 \mathrm{H}^{+}+2 \mathrm{e}^{-} \rightarrow\right.$ $\mathrm{HCOOH} ; \mathrm{CO}_{2}+6 \mathrm{H}^{+}+6 \mathrm{e}^{-} \rightarrow \mathrm{CH}_{3} \mathrm{OH}+\mathrm{H}_{2} \mathrm{O} ; \mathrm{CO}_{2}+8 \mathrm{H}^{+}$ $+8 \mathrm{e}^{-} \rightarrow \mathrm{CH}_{4}+2 \mathrm{H}_{2} \mathrm{O}$ ), which were much higher than those of Pt-modified carbon nanotubes and platinum carbon as cathode catalysts. This type of hybrid catalysts would effectively relieve global warming and develop a low-carbon economy.

So far, the research of graphene-supported metal SACs is still in the laboratory stage, and the performance is mainly focused on traditional chemical reactions such as $\mathrm{CO}$ oxidation. The dual advantages of SACs on graphene substrate should be exerted, and further large-scale industrial application should be applied to energy issues such as fuel cells to solve environmental problems in the future.

\section{CONCLUSION}

SACs have become an emerging trend in the field of heterogeneous catalysis in the past few years. The graphene-supported metal SACs, which combine the advantages of $2 \mathrm{D}$ graphene and single atom active sites, have promoted the development of SACs in the catalytic field as the medium between heterogeneous catalysis and homogeneous catalysis. Graphene-supported metal SACs could exhibit excellent catalytic ability in the fields of $\mathrm{CO}$ oxidation, oxidation of benzene to phenol, HER, MOR, ORR, hydrogenation and photoelectrocatalysis. With the development of techniques for preparation of high-quality graphene and SACs, graphene-supported metal SACs may realize large-scale fabrication and industrial applications in the future, which can achieve highly efficient and green catalysis. However, as a new field, there are still some challenges in SACs. Intrinsic theoretical understanding of the origination of the high catalytic performance is still in infancy. Graphene-supported metal SACs can be fabricated via ALD technology, yet there are still many challenges, such as low output, large energy consumption and low control accuracy. Therefore, scientists need to continuously improve scalable preparation techniques to achieve their industrial application in the near future. In conclusion, graphene-supported metal SACs have demonstrated potential in many reactions. The market prospect of graphene-supported SACs will be broad with the effort of researchers.

Received 17 December 2019; accepted 3 March 2020; published online 24 March 2020

1 Thomas JM, Saghi Z, Gai PL. Can a single atom serve as the active site in some heterogeneous catalysts? Top Catal, 2011, 54: 588594

2 Zhang $\mathrm{X}$, Shi $\mathrm{H}, \mathrm{Xu} \mathrm{BQ}$. Catalysis by gold: Isolated surface $\mathrm{Au}^{3+}$ ions are active sites for selective hydrogenation of 1,3-butadiene over $\mathrm{Au} / \mathrm{ZrO}_{2}$ catalysts. Angew Chem Int Ed, 2010, 44: 7132-7135

3 Vajda S, Pellin MJ, Greeley JP, et al. Subnanometre platinum clusters as highly active and selective catalysts for the oxidative dehydrogenation of propane. Nat Mater, 2009, 8: 213-216

4 Turner M, Golovko VB, Vaughan OPH, et al. Selective oxidation with dioxygen by gold nanoparticle catalysts derived from 55atom clusters. Nature, 2008, 454: 981-983

5 Qiao B, Wang A, Yang X, et al. Single-atom catalysis of CO oxidation using $\mathrm{Pt}_{1} / \mathrm{FeO}_{x}$. Nat Chem, 2011, 3: 634-641

6 Lin J, Wang A, Qiao B, et al. Remarkable performance of $\mathrm{Ir}_{1} / \mathrm{FeO}_{x}$ single-atom catalyst in water gas shift reaction. J Am Chem Soc, 2013, 135: 15314-15317

7 Wang A, Li J, Zhang T. Heterogeneous single-atom catalysis. Nat Rev Chem, 2018, 2: 65-81

8 Wang L, Huang L, Liang F, et al. Preparation, characterization and catalytic performance of single-atom catalysts. Chin J Catal, 2017, 38: 1528-1539

9 Yang XF, Wang A, Qiao B, et al. Single-atom catalysts: a new frontier in heterogeneous catalysis. Acc Chem Res, 2013, 46: $1740-1748$

10 Sahoo S, Reber AC, Khanna SN. Effect of location and filling of dstates on methane activation in single site Fe-based catalysts. Chem Phys Lett, 2016, 660: 48-54

11 Geim AK. Graphene: status and prospects. Science, 2009, 324: 1530-1534

12 Wu J, Pisula W, Müllen K. Graphenes as potential material for electronics. Chem Rev, 2007, 38: 718-747

$13 \mathrm{Su}$ Y, Li Z, Yu Y, et al. Composite structural modeling and tensile mechanical behavior of graphene reinforced metal matrix composites. Sci China Mater, 2018, 61: 112-124

14 Zheng S, Zeng M, Cao H, et al. Insight into the rapid growth of graphene single crystals on liquid metal via chemical vapor deposition. Sci China Mater, 2019, 62: 1087-1095 
15 Balandin AA, Ghosh S, Bao W, et al. Superior Thermal conductivity of single-layer graphene. Nano Lett, 2008, 8: 902-907

16 Wang $\mathrm{L}, \mathrm{Wu} \mathrm{B}, \mathrm{Liu} \mathrm{H}$, et al. Low temperature growth of clean single layer hexagonal boron nitride flakes and film for graphenebased field-effect transistors. Sci China Mater, 2019, 62: 12181225

17 Qin J, Zhou F, Xiao H, et al. Mesoporous polypyrrole-based graphene nanosheets anchoring redox polyoxometalate for allsolid-state micro-supercapacitors with enhanced volumetric capacitance. Sci China Mater, 2018, 61: 233-242

18 He DX, Qiu Y, Li LL, et al. Large-scale solvent-thermal synthesis of graphene/magnetite/conductive oligomer ternary composites for microwave absorption. Sci China Mater, 2015, 58: 566-573

19 Tombros N, Veligura A, Junesch J, et al. Large yield production of high mobility freely suspended graphene electronic devices on a polydimethylglutarimide based organic polymer. J Appl Phys, 2011, 109: 093702

20 Castro Neto AH, Guinea F, Peres NMR, et al. The electronic properties of graphene. Rev Mod Phys, 2009, 81: 109-162

21 Chae HK, Siberio-Pérez DY, Kim J, et al. A route to high surface area, porosity and inclusion of large molecules in crystals. Nature, 2004, 427: 523-527

22 Deng Y, Luo C, Zhang J, et al. Fast three-dimensional assembly of $\mathrm{MoS}_{2}$ inspired by the gelation of graphene oxide. Sci China Mater, 2019, 62: 745-750

23 Ibrahim WAW, Nodeh HR, Sanagi MM. Graphene-based materials as solid phase extraction sorbent for trace metal ions, organic compounds, and biological sample preparation. Critical Rev Anal Chem, 2016, 46: 267-283

24 Jin L, Huang L, Ren L, et al. Preparation of stable and highefficient poly $(m$-phenylenediamine)/reduced graphene oxide composites for hexavalent chromium removal. J Mater Sci, 2019, 54: $383-395$

25 Park S, Lee KS, Bozoklu G, et al. Graphene oxide papers modified by divalent ions-enhancing mechanical properties via chemical cross-linking. ACS Nano, 2008, 2: 572-578

26 Molina-García MA, Rees NV. "Metal-free" electrocatalysis: Quaternary-doped graphene and the alkaline oxygen reduction reaction. Appl Catal A-General, 2018, 553: 107-116

27 Chen F, Yang Q, Li X, et al. Hierarchical assembly of graphenebridged $\mathrm{Ag}_{3} \mathrm{PO}_{4} / \mathrm{Ag} / \mathrm{BiVO}_{4}(040) \mathrm{Z}$-scheme photocatalyst: an efficient, sustainable and heterogeneous catalyst with enhanced visible-light photoactivity towards tetracycline degradation under visible light irradiation. Appl Catal B-Environ, 2017, 200: 330342

28 Chen X, Yu L, Wang S, et al. Highly active and stable single iron site confined in graphene nanosheets for oxygen reduction reaction. Nano Energy, 2016, 32: 353-358

29 Guo S, Yuan N, Zhang G, et al. Graphene modified iron sludge derived from homogeneous fenton process as an efficient heterogeneous fenton catalyst for degradation of organic pollutants. Microporous Mesoporous Mater, 2017, 238: 62-68

30 Sun S, Zhang G, Gauquelin N, et al. Single-atom catalysis using Pt/graphene achieved through atomic layer deposition. Sci Rep, 2013, 3: 1775

31 Ta HQ, Zhao L, Yin W, et al. Single Cr atom catalytic growth of graphene. Nano Res, 2018, 11: 2405-2411

32 Yan $\mathrm{H}$, Cheng $\mathrm{H}$, Yi $\mathrm{H}$, et al. Single-atom $\mathrm{Pd}_{1} / \mathrm{graphene}$ catalyst achieved by atomic layer deposition: remarkable performance in selective hydrogenation of 1,3-butadiene. J Am Chem Soc, 2015,
137: 10484-10487

33 Ye $\mathrm{H}, \mathrm{Li}$ Y, Chen J, et al. PdCu alloy nanoparticles supported on reduced graphene oxide for electrocatalytic oxidation of methanol. J Mater Sci, 2018, 53: 15871-15881

34 Zhao J, Deng Q, Avdoshenko SM, et al. Direct in situ observations of single $\mathrm{Fe}$ atom catalytic processes and anomalous diffusion at graphene edges. Proc Natl Acad Sci USA, 2014, 111: 15641-15646

35 Liang $\mathrm{Y}, \mathrm{Li} \mathrm{Y}$, Wang $\mathrm{H}$, et al. $\mathrm{Co}_{3} \mathrm{O}_{4}$ nanocrystals on graphene as a synergistic catalyst for oxygen reduction reaction. Nat Mater, 2011, 10: 780-786

36 Li Y, Wang H, Xie L, et al. $\mathrm{MoS}_{2}$ nanoparticles grown on graphene: an advanced catalyst for the hydrogen evolution reaction. J Am Chem Soc, 2011, 133: 7296-7299

37 Scholz D, Kröcher O, Vogel F. Deactivation and regeneration of sulfonated carbon catalysts in hydrothermal reaction environments. ChemSusChem, 2018, 11: 2189-2201

38 Wu P, Du P, Zhang H, et al. Graphyne-supported single Fe atom catalysts for CO oxidation. Phys Chem Chem Phys, 2015, 17: 1441-1449

39 Liu X, Sui Y, Duan T, et al. CO oxidation catalyzed by Pt-embedded graphene: a first-principles investigation. Phys Chem Chem Phys, 2014, 16: 23584-23593

40 Zhang X, Lu Z, Xu G, et al. Single Pt atom stabilized on nitrogen doped graphene: $\mathrm{CO}$ oxidation readily occurs via the tri-molecular Eley-Rideal mechanism. Phys Chem Chem Phys, 2015, 17: 20006-20013

41 Deng D, Chen X, Yu L, et al. A single iron site confined in a graphene matrix for the catalytic oxidation of benzene at room temperature. Sci Adv, 2015, 1: e1500462

42 Yan $\mathrm{M}$, Hua $\mathrm{Y}$, Zhu $\mathrm{F}$, et al. Constructing nitrogen doped graphene quantum dots- $\mathrm{ZnNb}_{2} \mathrm{O}_{6} / \mathrm{g}_{\mathrm{g}}-\mathrm{C}_{3} \mathrm{~N}_{4}$ catalysts for hydrogen production under visible light. Appl Catal B-Environ, 2017, 206: 531-537

43 Fei H, Dong J, Arellano-Jiménez MJ, et al. Atomic cobalt on nitrogen-doped graphene for hydrogen generation. Nat Commun, 2015, 6: 8668

44 Yoo EJ, Okata T, Akita T, et al. Enhanced electrocatalytic activity of Pt subnanoclusters on graphene nanosheet surface. Nano Lett, 2009, 9: 2255-2259

45 Li Y, Gao W, Ci L, et al. Catalytic performance of Pt nanoparticles on reduced graphene oxide for methanol electro-oxidation. Carbon, 2010, 48: 1124-1130

46 Zhao Y, Zhan L, Tian J, et al. Enhanced electrocatalytic oxidation of methanol on $\mathrm{Pd} /$ polypyrrole-graphene in alkaline medium. Electrochim Acta, 2011, 56: 1967-1972

47 Lefèvre M, Proietti E, Jaouen F, et al. Iron-based catalysts with improved oxygen reduction activity in polymer electrolyte fuel cells. Science, 2009, 324: 71-74

48 Stambula S, Gauquelin N, Bugnet M, et al. Chemical structure of nitrogen-doped graphene with single platinum atoms and atomic clusters as a platform for the PEMFC electrode. J Phys Chem C, 2014, 118: 3890-3900

49 Lu Y, Liu M, Nie H, et al. Direct fabrication of metal-free hollow graphene balls with a self-supporting structure as efficient cathode catalysts of fuel cell. J Nanopart Res, 2016, 18: 160

50 Shao Y, Zhang S, Kou R, et al. Noncovalently functionalized graphitic mesoporous carbon as a stable support of Pt nanoparticles for oxygen reduction. J Power Sources, 2010, 195: 18051811 
51 Nie R, Miao M, Du W, et al. Selective hydrogenation of C-C bond over $\mathrm{N}$-doped reduced graphene oxides supported Pd catalyst. Appl Catal B-Environ, 2016, 180: 607-613

52 Ahmed SN, Haider W. Heterogeneous photocatalysis and its potential applications in water and wastewater treatment: a review. Nanotechnology, 2018, 29: 342001

53 Prasad M, Sharma V, Aher R, et al. Synergistic effect of Ag plasmon- and reduced graphene oxide-embedded $\mathrm{ZnO}$ nanorodbased photoanodes for enhanced photoelectrochemical activity. J Mater Sci, 2017, 52: 13572-13585

54 Song X, Shi Q, Wang H, et al. Preparation of Pd-Fe/graphene catalysts by photocatalytic reduction with enhanced electrochemical oxidation-reduction properties for chlorophenols. Appl Catal B-Environ, 2017, 203: 442-451

55 Cheng J, Zhang M, Wu G, et al. Photoelectrocatalytic reduction of $\mathrm{CO}_{2}$ into chemicals using Pt-modified reduced graphene oxide combined with Pt-modified $\mathrm{TiO}_{2}$ nanotubes. Environ Sci Technol, 2014, 48: 7076-7084

56 Yoshitake T, Shimakawa Y, Kuroshima S, et al. Preparation of fine platinum catalyst supported on single-wall carbon nanohorns for fuel cell application. Physica B-Condensed Matter, 2002, 323: 124-126

57 Jones J, Xiong H, DeLaRiva AT, et al. Thermally stable singleatom platinum-on-ceria catalysts via atom trapping. Science, 2016, 353: 150-154

58 Allen JE, Hemesath ER, Perea DE, et al. High-resolution detection of Au catalyst atoms in Si nanowires. Nat Nanotech, 2008, 3: 168173

59 Kolmakov A, Klenov DO, Lilach Y, et al. Enhanced gas sensing by individual $\mathrm{SnO}_{2}$ nanowires and nanobelts functionalized with Pd catalyst particles. Nano Lett, 2005, 5: 667-673

60 Kim HM, Kim K, Lee CY, et al. Electrical conductivity and electromagnetic interference shielding of multiwalled carbon nanotube composites containing Fe catalyst. Appl Phys Lett, 2004, 84: 589-591

61 Blomquist $\mathrm{J}$, Lång $\mathrm{H}$, Larsson $\mathrm{R}$, et al. Pyrolysis behaviour of metalloporphyrins. Part 2-A Mössbauer study of pyrolysed $\mathrm{Fe}^{\mathrm{III}}$ tetraphenylporphyrin chloride. J Chem Soc Faraday Trans, 1992, 88: 2007-2011

62 Jiao L, Wan G, Zhang R, et al. From metal-organic frameworks to single-atom $\mathrm{Fe}$ implanted N-doped porous carbons: Efficient oxygen reduction in both alkaline and acidic media. Angew Chem Int Ed, 2018, 57: 8525-8529

63 Liu W, Zhang L, Yan W, et al. Single-atom dispersed Co-N-C catalyst: structure identification and performance for hydrogenative coupling of nitroarenes. Chem Sci, 2016, 7: 5758-5764

64 Wan G, Yang C, Zhao W, et al. Anion-regulated selective generation of cobalt sites in carbon: Toward superior bifunctional electrocatalysis. Adv Mater, 2017, 29: 1703436-1703443

65 Zhu C, Shi Q, Xu BZ, et al. Hierarchically porous M-N-C (M = $\mathrm{Co}$ and $\mathrm{Fe}$ ) single-atom electrocatalysts with robust $\mathrm{MN}_{x}$ active moieties enable enhanced ORR performance. Adv Energy Mater, 2018, 8: 1801956-1801963

66 Xu BQ, Wei JM, Wang HY, et al. Nano-MgO: novel preparation and application as support of $\mathrm{Ni}$ catalyst for $\mathrm{CO}_{2}$ reforming of methane. Catal Today, 2001, 68: 217-225

67 Jabri A, Temple C, Crewdson $\mathrm{P}$, et al. Role of the metal oxidation state in the SNS-Cr catalyst for ethylene trimerization: isolation of di- and trivalent cationic intermediates. J Am Chem Soc, 2006, 128: $9238-9247$
68 Sakthivel S, Shankar MV, Palanichamy M, et al. Enhancement of photocatalytic activity by metal deposition: characterisation and photonic efficiency of $\mathrm{Pt}, \mathrm{Au}$ and $\mathrm{Pd}$ deposited on $\mathrm{TiO}_{2}$ catalyst. Water Res, 2004, 38: 3001-3008

69 Stagg-Williams SM, Noronha FB, Fendley G, et al. $\mathrm{CO}_{2}$ reforming of $\mathrm{CH}_{4}$ over $\mathrm{Pt} / \mathrm{ZrO}_{2}$ catalysts promoted with $\mathrm{La}$ and Ce oxides. J Catal, 2000, 194: 240-249

70 Llorca J, de la Piscina PR1, Dalmon JA, et al. CO-free hydrogen from steam-reforming of bioethanol over $\mathrm{ZnO}$-supported cobalt catalysts. Appl Catal B-Environ, 2003, 43: 355-369

71 Abbet S, Sanchez A, Heiz U, et al. Acetylene cyclotrimerization on supported size-selected $\mathrm{Pd}_{n}$ clusters $(1 \leq n \leq 30)$ : One atom is enough! J Am Chem Soc, 2000, 122: 3453-3457

72 Qiao B, Liu J, Wang YG, et al. Highly efficient catalysis of preferential oxidation of $\mathrm{CO}$ in $\mathrm{H}_{2}$-rich stream by gold single-atom catalysts. ACS Catal, 2015, 5: 6249-6254

73 Zhang H, Kawashima K, Okumura M, et al. Colloidal Au singleatom catalysts embedded on Pd nanoclusters. J Mater Chem A, 2014, 2: 13498-13508

74 Guo X, Fang G, Li G, et al. Direct, nonoxidative conversion of methane to ethylene, aromatics, and hydrogen. Science, 2014, 344: 616-619

75 Guo S, Ma L, Song G, et al. Covalent grafting of triazine derivatives onto graphene oxide for preparation of epoxy composites with improved interfacial and mechanical properties. J Mater Sci, 2018, 53: 16318-16330

76 Li J, Tang X, Yi H, et al. Effects of copper-precursors on the catalytic activity of $\mathrm{Cu} /$ graphene catalysts for the selective catalytic oxidation of ammonia. Appl Surf Sci, 2017, 412: 37-44

77 Niu Y, Huang X, Wu X, et al. One-pot synthesis of Co/N-doped mesoporous graphene with embedded $\mathrm{Co} / \mathrm{CoO}_{x}$ nanoparticles for efficient oxygen reduction reaction. Nanoscale, 2017, 9: 1023310239

78 Primo A, Atienzar P, Sanchez E, et al. From biomass wastes to large-area, high-quality, $\mathrm{N}$-doped graphene: catalyst-free carbonization of chitosan coatings on arbitrary substrates. Chem Commun, 2012, 48: 9254-9256

79 Ren X, Liao B, Li Y, et al. Facile synthesis of PdSnCo/nitrogendoped reduced graphene as a highly active catalyst for lithium-air batteries. Electrochim Acta, 2017, 228: 36-44

80 Wang H, Xiao H, Lu Y, et al. The catalytic effect of boron nitride on the mechanical properties of polyacrylonitrile-based carbon fiber. J Mater Sci, 2016, 51: 10690-10700

81 Wang H, Zhang X, Takamatsu H. Ultraclean suspended monolayer graphene achieved by in situ current annealing. Nanotechnology, 2017, 28: 045706

82 Yan $\mathrm{H}$, Lin $\mathrm{Y}, \mathrm{Wu} \mathrm{H}$, et al. Bottom-up precise synthesis of stable platinum dimers on graphene. Nat Commun, 2017, 8: 1070-1081

83 Wang T, Wang J, Wang X, et al. Graphene-templated synthesis of sandwich-like porous carbon nanosheets for efficient oxygen reduction reaction in both alkaline and acidic media. Sci China Mater, 2018, 61: 915-925

84 Sahoo S, Suib SL, Alpay SP. Graphene supported single atom transition metal catalysts for methane activation. ChemCatChem, 2018, 10: 3229-3235

85 Robertson AW, Montanari B, He K, et al. Dynamics of single Fe atoms in graphene vacancies. Nano Lett, 2013, 13: 1468-1475

86 Zhang X, Guo J, Guan P, et al. Catalytically active single-atom niobium in graphitic layers. Nat Commun, 2013, 4: 1924

87 Wang WL, Santos EJG, Jiang B, et al. Direct observation of a 
long-lived single-atom catalyst chiseling atomic structures in graphene. Nano Lett, 2016, 14: 450-455

88 Yang HB, Hung SF, Liu S, et al. Atomically dispersed $\mathrm{Ni}(\mathrm{I})$ as the active site for electrochemical $\mathrm{CO}_{2}$ reduction. Nat Energy, 2018, 3: $140-147$

89 Huang ML, Chang YC, Chang $\mathrm{CH}$, et al. Surface passivation of III-V compound semiconductors using atomic-layer-depositiongrown $\mathrm{Al}_{2} \mathrm{O}_{3}$. Appl Phys Lett, 2005, 87: 252104-252107

$90 \mathrm{Kim} \mathrm{H}$. Atomic layer deposition of metal and nitride thin films: current research efforts and applications for semiconductor device processing. J Vac Sci Technol B, 2003, 21: 2231-2261

91 Sneh O, Clark-Phelps RB, Londergan AR, et al. Thin film atomic layer deposition equipment for semiconductor processing. Thin Solid Films, 2002, 402: 248-261

$92 \mathrm{Ahn} \mathrm{KY}$, Forbes L. Atomic layer deposited nanolaminates of $\mathrm{HfO}_{2} / \mathrm{ZrO}_{2}$ films as gate dielectrics. US Patent, 20040023461, 2007

93 Elam JW, Sechrist ZA, George SM. $\mathrm{ZnO} / \mathrm{Al}_{2} \mathrm{O}_{3}$ nanolaminates fabricated by atomic layer deposition: growth and surface roughness measurements. Thin Solid Films, 2002, 414: 43-55

94 Lim BS, Rahtu A, de Rouffignac P, et al. Atomic layer deposition of lanthanum aluminum oxide nano-laminates for electrical applications. Appl Phys Lett, 2004, 84: 3957-3959

95 Shao Y, Zhang S, Wang C, et al. Highly durable graphene nanoplatelets supported Pt nanocatalysts for oxygen reduction. J Power Sources, 2010, 195: 4600-4605

96 Li W, Liang C, Zhou W, et al. Preparation and characterization of multiwalled carbon nanotube-supported platinum for cathode catalysts of direct methanol fuel cells. J Phys Chem B, 2003, 107: 6292-6299

97 Koningsberger DC, Mojet BL, van Dorssen GE, et al. XAFS spectroscopy; fundamental principles and data analysis. Top Catal, 2000, 10: 143-155

98 Browning ND, Chisholm MF, Pennycook SJ. Atomic-resolution chemical analysis using a scanning transmission electron microscope. Nature, 1993, 366: 143-146

99 Li C, Yang G. The principle and applications of STEM and EELS. Physics, 2014, 43: 597-605

100 Zhao W, Wan G, Peng C, et al. Key single-atom electrocatalysis in metal-organic framework (MOF)-derived bifunctional catalysts. ChemSusChem, 2018, 11: 3473-3479

101 Greca F, Hares MM, Nevah E, et al. A randomized trial to compare rubber band ligation with phenol injection for treatment of hemorrhoids. Br J Surg, 1981, 68: 250-252

102 Rengaraj S. Removal of phenol from aqueous solution and resin manufacturing industry wastewater using an agricultural waste: rubber seed coat. J Hazard Mater, 2002, 89: 185-196

103 El-Naas MH, Al-Zuhair S, Alhaija MA. Removal of phenol from petroleum refinery wastewater through adsorption on date-pit activated carbon. Chem Eng J, 2010, 162: 997-1005

104 Wagner M, Nicell JA. Peroxidase-catalyzed removal of phenols from a petroleum refinery wastewater. Water Sci Tech, 2001, 43: 253-260
105 Lai TL, Lai YL, Lee CC, et al. Microwave-assisted rapid fabrication of $\mathrm{Co}_{3} \mathrm{O}_{4}$ nanorods and application to the degradation of phenol. Catal Today, 2008, 131: 105-110

106 Pradhan GK, Padhi DK, Parida KM. Fabrication of $\alpha-\mathrm{Fe}_{2} \mathrm{O}_{3}$ nanorod/RGO composite: A novel hybrid photocatalyst for phenol degradation. ACS Appl Mater Interfaces, 2013, 5: 9101-9110

107 Iwamoto M, Hirata J, Matsukami K, et al. Catalytic oxidation by oxide radical ions. 1. One-step hydroxylation of benzene to phenol over group 5 and 6 oxides supported on silica gel. J Phys Chem, 1983, 87: 903-905

108 Bak T, Nowotny J, Rekas M, et al. Photo-electrochemical hydrogen generation from water using solar energy. Materials-related aspects. Int J Hydrogen Energy, 2002, 27: 991-1022

109 O'M Bockris J. On hydrogen futures: toward a sustainable energy system. Int J Hydrogen Energy, 2003, 28: 131-133

110 Turner JA. Sustainable hydrogen production. Science, 2004, 305: 972-974

111 Cao Y, Hu P, Pan W, et al. Methanal and xylene sensors based on $\mathrm{ZnO}$ nanoparticles and nanorods prepared by room-temperature solid-state chemical reaction. Sens Actuat B-Chem, 2008, 134: 462-466

112 Watanabe M, Motoo S. Electrocatalysis by ad-atoms. J Electroanal Chem Interfacial Electrochem, 1975, 60: 267-273

113 Liu $\mathrm{H}$, Song $\mathrm{C}$, Zhang L, et al. A review of anode catalysis in the direct methanol fuel cell. J Power Sources, 2006, 155: 95-110

114 Steele BCH, Heinzel A. Materials for fuel-cell technologies. Nature, 2001, 414: 345-352

115 Proietti E, Jaouen F, Lefèvre M, et al. Iron-based cathode catalyst with enhanced power density in polymer electrolyte membrane fuel cells. Nat Commun, 2011, 2: 416-425

116 Kramm UI, Herrmann-Geppert I, Behrends J, et al. On an easy way to prepare metal-nitrogen doped carbon with exclusive presence of $\mathrm{MeN}_{4}$-type sites active for the ORR. J Am Chem Soc, 2016, 138: 635-640

117 Wan G, Lin XM, Wen J, et al. Tuning the performance of singleatom electrocatalysts: support-induced structural reconstruction. Chem Mater, 2018, 30: 7494-7502

118 Wan G, Yu P, Chen $\mathrm{H}$, et al. Engineering single-atom cobalt catalysts toward improved electrocatalysis. Small, 2018, 14: 1704319-1704325

Acknowledgements This work was financially supported by the National Natural Science Foundation of China (51502166 and 51881220658), and the Scientific Research Program Funded by Shaanxi Provincial Department (17JK0130).

Author contributions Ren $S$ wrote and revised the manuscript with support from Yu Q; Yu X, Rong P, Jiang L and Jiang J actively discussed the original idea of this review, polished the manuscript and organized the references. All authors contributed to the general discussion.

Conflict of interest The authors declare that they have no conflict of interest. 


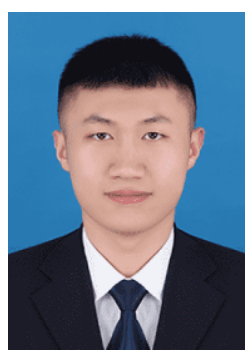

Shuai Ren was born in 1994. He is now pursuing his Master degree in the School of Materials Science and Engineering, Shaanxi University of Technology, Hanzhong, China. His research interest is the preparation of graphene materials and the development of functional devices.

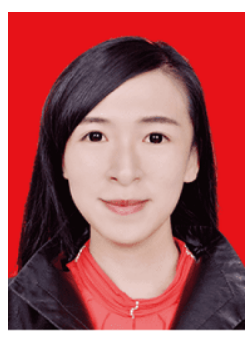

Qi Yu obtained her BSc, MSc and PhD degrees from Jilin University. Now she is an associate professor at the Institute of Graphene at Shaanxi Key Laboratory of Catalysis, Shaanxi University of Technology. Her research interests include fabrication, characterization and properties of nanomaterials, including $\mathrm{ZnO} / \mathrm{PET}-\mathrm{ITO}, \mathrm{ZnO} /$ diamond, and graphene composite structures fabricated by magnetron sputtering or hydrothermal technique.

\section{石墨烯基金属单原子催化剂: 综述}

任帅 ${ }^{1}$, 于琦 $^{{ }^{*}}$, 于小虎 ${ }^{2}$, 容萍 ${ }^{1}$, 姜立运 ${ }^{3}$, 蒋剑超 ${ }^{1}$

摘要 单原子催化剂具有较高的活性、选择性和稳定性, 已成为多 相催化领域的一个新兴前沿趋势. 通过将催化反应中活性金属原 子的尺寸减小到单原子尺度, 单原子催化剂可以大幅提高活性金 属原子在众多催化反应中的有效性. 石墨烯基金属单原子催化剂 也因其独特的晶格结构和物理化学性质而备受关注, 使其在一些 化学反应中表现出了优异的活性和选择性. 本文综述了近年来石 墨烯基金属单原子催化剂的制备方法、先进表征手段及优点, 重 点介绍了其在一氧化碳氧化、苯氧化制苯酚、析氢反应、甲醇氧 化反应、氧还原反应、加氢及光电催化等方面的应用. 最后, 我们 对石墨烯基金属单原子催化剂未来的产业化发展提出了建议. 